Article

\title{
Quantifying Aboveground Biomass of Shrubs Using Spectral and Structural Metrics Derived from UAS Imagery
}

\author{
Lucy G. Poley ${ }^{1, *}$, David N. Laskin ${ }^{2}\left(\mathbb{D}\right.$ and Gregory J. McDermid ${ }^{1}$ (1) \\ 1 Department of Geography, University of Calgary, Calgary, AB T2N 1N4, Canada; mcdermid@ucalgary.ca \\ 2 Parks Canada, Banff National Park, Banff, AB T1L 1K2, Canada; david.laskin@canada.ca \\ * Correspondence: lgpoley@ucalgary.ca
}

Received: 3 June 2020; Accepted: 6 July 2020; Published: 9 July 2020

check for updates

\begin{abstract}
Shrub-dominated ecosystems support biodiversity and play an important storage role in the global carbon cycle. However, it is challenging to characterize biophysical properties of low-stature vegetation like shrubs from conventional ground-based or remotely sensed data. We used spectral and structural variables derived from high-resolution unmanned aerial system (UAS) imagery to estimate the aboveground biomass of shrubs in the Betula and Salix genera in a montane meadow in Banff National Park, Canada using an area-based approach. In single-variable linear regression models, visible light (RGB) indices outperformed multispectral or structural data. A linear model based on the red ratio vegetation index (VI) accumulated over shrub area could model biomass (calibration $R^{2}=0.888$; validation $R^{2}=0.774$ ) nearly as well as the top multivariate linear regression models (calibration $\mathrm{R}^{2}=0.896$; validation $\mathrm{R}^{2}>0.750$ ), which combined an accumulated RGB VI with a multispectral metric. The excellent performance of accumulated RGB VIs represents a novel approach to fine-scale vegetation biomass estimation, fusing spectral and spatial information into a single parsimonious metric that rivals the performance of more complex multivariate models. Methods developed in this study will be relevant to researchers interested in estimating fine-scale shrub aboveground biomass within a range of ecosystems.
\end{abstract}

Keywords: aboveground biomass; shrubs; vegetation indices; RGB; multispectral; canopy height model; UAS; rangelands; plains bison

\section{Introduction}

Ecosystems of mixed herbaceous and woody vegetation cover over one fifth of the Earth's surface [1], supporting significant global biodiversity and wildlife habitat as well as providing ecosystem services such as water and soil conservation and livestock grazing [2-6]. The woody vegetation in these environments, often dominated by shrub species, also plays an important role in the global carbon cycle [6,7], storing up to $30 \%$ of global terrestrial carbon in above- and belowground biomass [8]. The ability of shrubs to store carbon, produce food for wildlife and livestock, and provide ecosystem services is closely linked to their distribution, physical structure, and biomass. These characteristics are dynamic across space and time and increasingly impacted by human development and climatic changes [1,7,9-11]. In some shrub-dominated environments, the number, size, and distribution of shrubs is decreasing $[10,12-14]$, potentially impacting the ecosystem services and interactions they bestow $[15,16]$. In other environments, the encroachment of shrubs into previously-unoccupied ecosystems presents a conservation concern [17-20].

However, there has been less focus on modelling aboveground biomass (AGB) in shrub-dominated ecosystems compared to environments such as forests. It is more difficult to accurately characterize 
low-stature vegetation [21] and there is less economic interest in shrubs [22], which are considered unwanted "nuisance species" in some areas $[17,23]$. As a result, efficient methods for measuring and monitoring shrub biomass across ecosystems are relatively poorly developed.

It can be challenging to characterize shrub AGB with conventional remote sensing methods because shrub-dominated vegetation communities tend to be spatially heterogeneous at fine scales, spectrally indistinct, and low in stature $[6,7,15]$. However, in recent years there has been an increase in the use of unmanned aerial systems (UASs) as remote-sensing platforms [24-29]. A significant advantage of UAS-based remote sensing is the ability to simultaneously collect very high-resolution data on the structural and spectral characteristics of vegetation at scales suitable for detecting small or low-growing plants [5,30-33]. Despite a demonstrated ability of UAS data to estimate the fine-scale AGB of vegetation including arable and non-arable crops [26,32-39], trees [28,31,40-43], mangrove and wetland plants [44-46], and grasses [2,5,47,48], comparatively few studies have used UAS data for shrub biomass estimation. For example, Cunliffe et al. [9] found that structural metrics of shrub height derived from a canopy height model (CHM) could accurately estimate shrub AGB in a dryland ecosystem in the southwestern USA. The opportunity thus exists to more broadly explore the use of UAS-derived data for determining the biomass of shrub species in other ecosystems and to test which data type(s) (i.e., spectral, structural) are most accurately able to estimate shrub AGB.

In many rangeland environments, including shrublands, large ungulate grazers and periodic fires have historically played significant roles in shaping vegetation community structure and biodiversity [49]. The frequency and intensity of these disturbances are critical to habitat heterogeneity and ecological processes at multiple spatial scales [50]. However, most rangeland management practices have been developed to increase livestock production and favour a few key forage species rather than promote a heterogeneous distribution of vegetation across the landscape [51]. Restoring the natural ecological function of grazers and managing rangelands for heterogeneity is increasingly recognized as a key component of successful large-scale conservation of biodiversity and ecosystem integrity in rangelands [51-53].

With this goal in mind, plains bison (Bison bison bison) were reintroduced in 2018 to Banff National Park in Canada, a region bison have been absent from since their extirpation in the 1800s [54]. Plains bison play a keystone role in ecosystems, impacting and altering vegetation communities through browsing, grazing, roaming, and wallowing [55]. Efficient and accurate methods of monitoring the distribution and abundance of vegetation in the region occupied by the newly reintroduced bison are needed to support park management and quantify their impact on the ecosystem. The fine spatial and temporal resolution of bison-vegetation dynamics makes the use of either ground-based or traditional aerial remote sensing for detecting these processes challenging. However, it is an ideal setting to investigate whether UAS imagery can be used to estimate and track changes in shrub AGB and distribution over time as bison occupy this landscape once again.

Our overall objective in the work reported in this manuscript was to develop a workflow for estimating shrub AGB using data collected from UAS surveys. To achieve that, we sought to answer the following primary research questions: (i) which structural and/or spectral variables have the highest correlations with allometric AGB, (ii) which structural and/or spectral variables best predict allometric AGB in regression models, and (iii) are the best AGB estimation models robust enough to be applied to another spatially distinct location? In addition to these primary research questions, we had a set of secondary follow-up questions: (i) are the remote-sensing models sensitive enough to detect simulated ungulate browsing of shrubs and (ii) what is the total shrub aboveground biomass across the study site? While this study was conducted within the context of bison reintroduction to Banff National Park, our methods and results are informative for researchers interested in developing similar models of shrub biomass from UAS data in other rangeland ecosystems or for other ecological applications. 


\section{Materials and Methods}

\subsection{Study Area}

Our fieldwork was conducted within the Panther River Valley in Banff National Park in the Rocky Mountains of Alberta, Canada (Figure 1). This area was determined to have the highest carrying capacity and best habitat suitability for bison within the park due to current habitat conditions and past evidence of bison occupation [54]. Banff National Park was established as a protected region in 1885 and has an area of $6641 \mathrm{~km}^{2}$. The park is characterized by its climate of short, dry summers and long cold winters as well as its extremely mountainous terrain, broken up by large valleys $2-5 \mathrm{~km}$ wide [54]. The Panther River is shallow throughout its gravel bed and flows in a north-easterly direction from its headwaters towards the eastern boundary of the park. Common vegetation in the river valley includes intermittent stands of Douglas fir (Pseudotsuga menziesii), white spruce (Picea glauca), and aspen (Populus tremuloides) interspersed with open grasslands with abundant forbs, graminoids, and shrubs including species of the Betula (birch) and Salix (willow) genera [56].

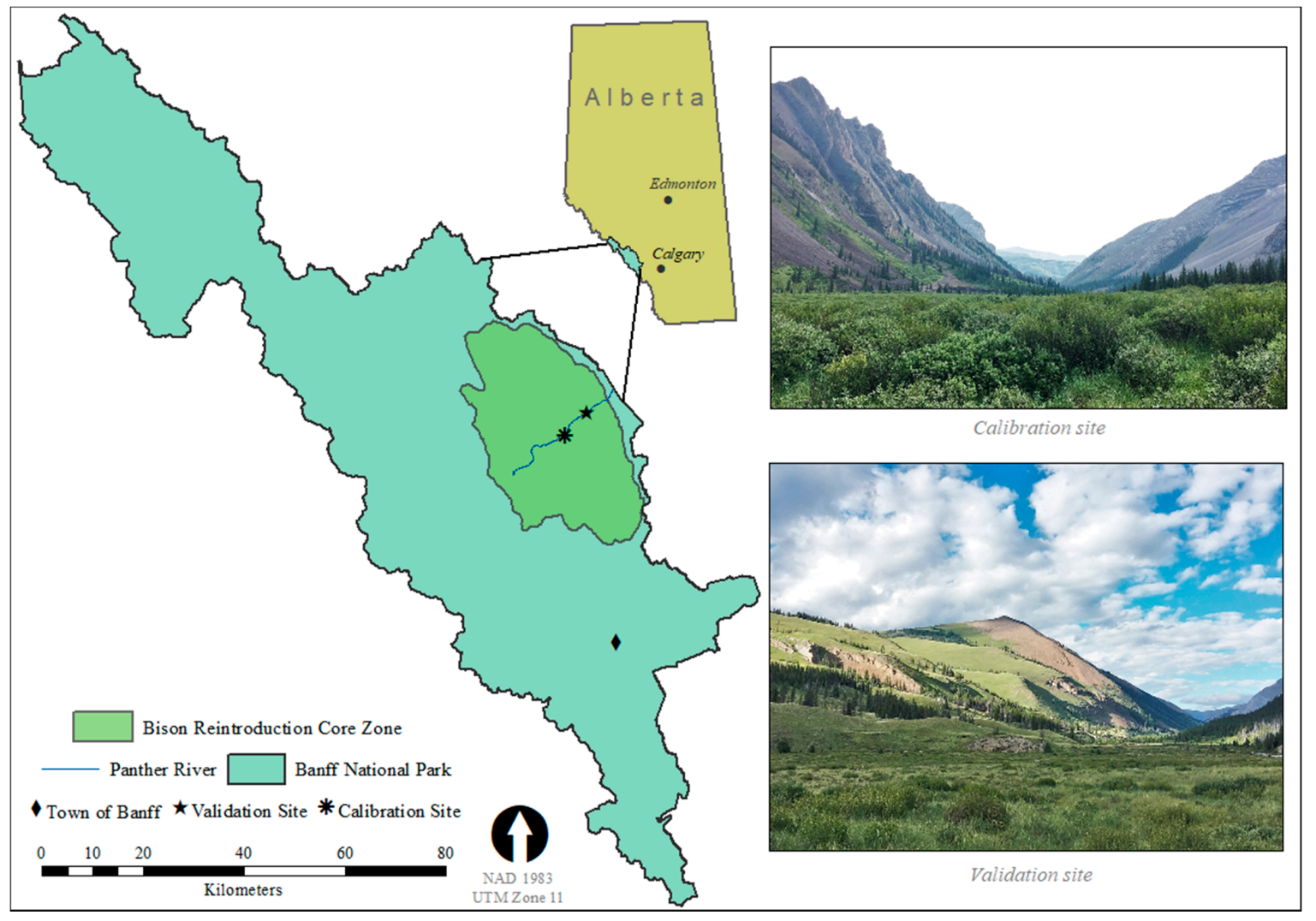

Figure 1. Location of the calibration and validation study sites within the core bison reintroduction zone in Banff National Park, Alberta, Canada, at which ground-based and unmanned aerial system (UAS) data on shrub aboveground biomass were collected in July of 2019.

\subsection{Site and Plot Selection}

We conducted our fieldwork at two different sites within the Panther River Valley located approximately $40 \mathrm{~km}$ north of the Banff town site (Figure 1). The first site (calibration site) was where all destructive ground-based sampling took place. This site was selected due to the abundance and diversity of sizes of shrubs in the Betula and Salix genera, lack of hazards for UAS flying, and proximity to a warden cabin for logistics. The second site (validation site) was located $6.6 \mathrm{~km}$ northeast of the calibration site along the Panther River and was selected due to its similar vegetative characteristics and geographic separation from the calibration site. 
At the calibration site, we selected individual shrubs for destructive sampling (Figure 2a) using a multi-stage sampling strategy comprised of a systematic primary stage and stratified-random secondary stage. In the primary stage, we started at the west end of each of five 125-m long transects across the study site and progressed eastward using a compass and GPS. On each transect we stopped every $20 \mathrm{~m}$ to locate a set of "suitable" shrubs: individuals reasonably distinct from their neighbours so that they could be removed cleanly during sampling. At each measurement point along the transect we marked the nearest three suitable shrubs in each of the Betula and Salix genera and recorded the GPS location, size (small, medium, or large relative to other shrubs), and genus of each shrub using a Hemisphere S320 GPS unit with $10 \mathrm{~mm}$ horizontal precision. After the five transects were complete, we had obtained a potential sampling pool of 90 shrubs of each genus. In the secondary stage, we selected 30 shrubs of each genus using a stratified-random approach: 10 shrubs randomly selected from each of the strata of small, medium, and large size classes.

At the validation site the sampling was non-destructive, so it was particularly important that each shrub be distinct from its neighbours to ensure we would only measure stems of that shrub during sampling and that the outline of each shrub would be obvious in aerial imagery. At each of the centre, northeast, northwest, southeast, and southwest ground control point (GCP) locations, we observed the nearest shrubs of each genus and selected one of each size class (small, medium, and large) of suitable, distinct Salix and Betula shrubs for non-destructive sampling (Figure 2b), resulting in a sample of 15 of each genera of shrub, five in each size class.

\subsection{Ground-Based Biomass Data Collection and Allometric Equations}

Figure 3 shows the order of steps taken during the data collection and analysis workflow used in this study. At the calibration site we collected ground-based measurements of shrub biomass in July 2018. After sample shrubs were selected (number 1 in grey circle in Figure 3), we conducted one visible light (RGB) and one multispectral (MS) UAS survey of the calibration site (2). Then, we simulated ungulate browsing by trimming the leaves and terminal ends of stems off each shrub in the sample (3) and conducted an RGB survey of the site with the browsed shrubs clearly marked in the imagery (4). Lastly, we cut each stem at the base ensuring that we did not cut below the soil level. We recorded the basal stem diameter (BSD) in mm and the number of stems of each shrub we removed (5).

At the validation site, we flew one RGB and one MS survey prior to taking any measurements. Next, we measured the BSD in millimetres of every stem of each selected Betula and Salix shrub without removing any stems. Flagging tape in the same patterns as at the calibration site, laid over the top of each measured shrub, was used to indicate shrub genus and location, and we conducted a final RGB survey to collect images with shrub markers.

Allometric equations for shrub AGB estimation derived previously in our study area [57] were used to estimate shrub AGB. Models have an exponential form $\left(y=a e^{b x}\right)$ where $y$ is biomass $(g)$ and $x$ is the basal stem diameter $(\mathrm{mm})$. We used the allometric equations to estimate leaf biomass $(\mathrm{a}=6.3794$, $\mathrm{b}=0.0918)$ and twig biomass $(\mathrm{a}=12.282, \mathrm{~b}=0.0854)$ for each measured stem in each shrub from the BSD measurements, then summed the biomass for all stems in the shrub to get a measure of leaf, twig, and total aboveground biomass in grams for each shrub. 


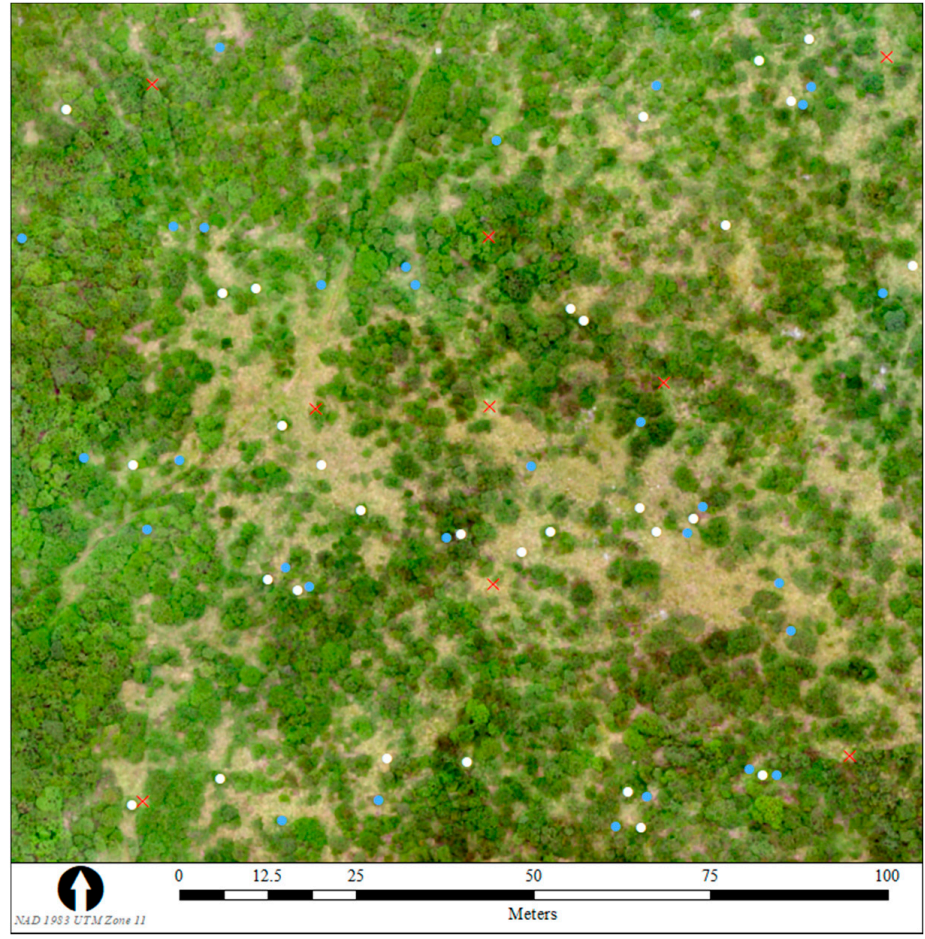

(a)

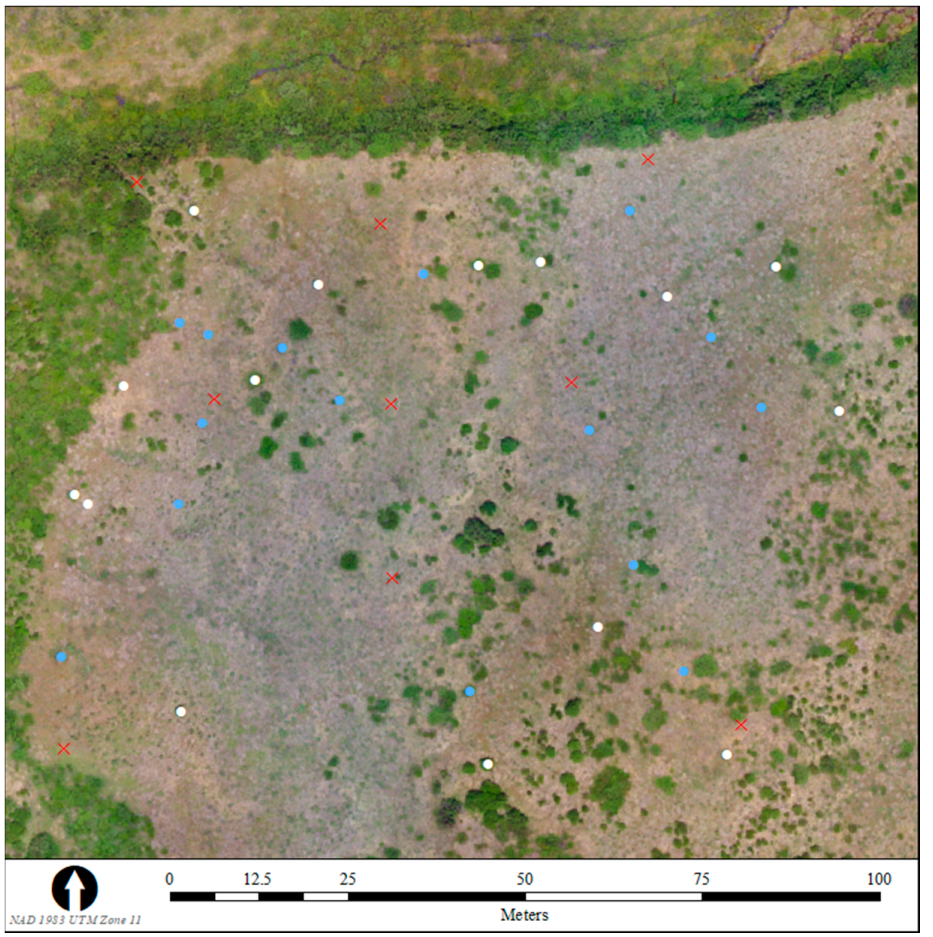

(b)

Figure 2. Orthomosaics of the (a) calibration and (b) validation sites in Banff National Park, Alberta, Canada, at which UAS surveys were flown and ground-based biomass measurements collected for selected shrubs in the Betula (blue dots) and Salix (white dots) genera. Red crosses show the locations of the nine ground control points at each site. 


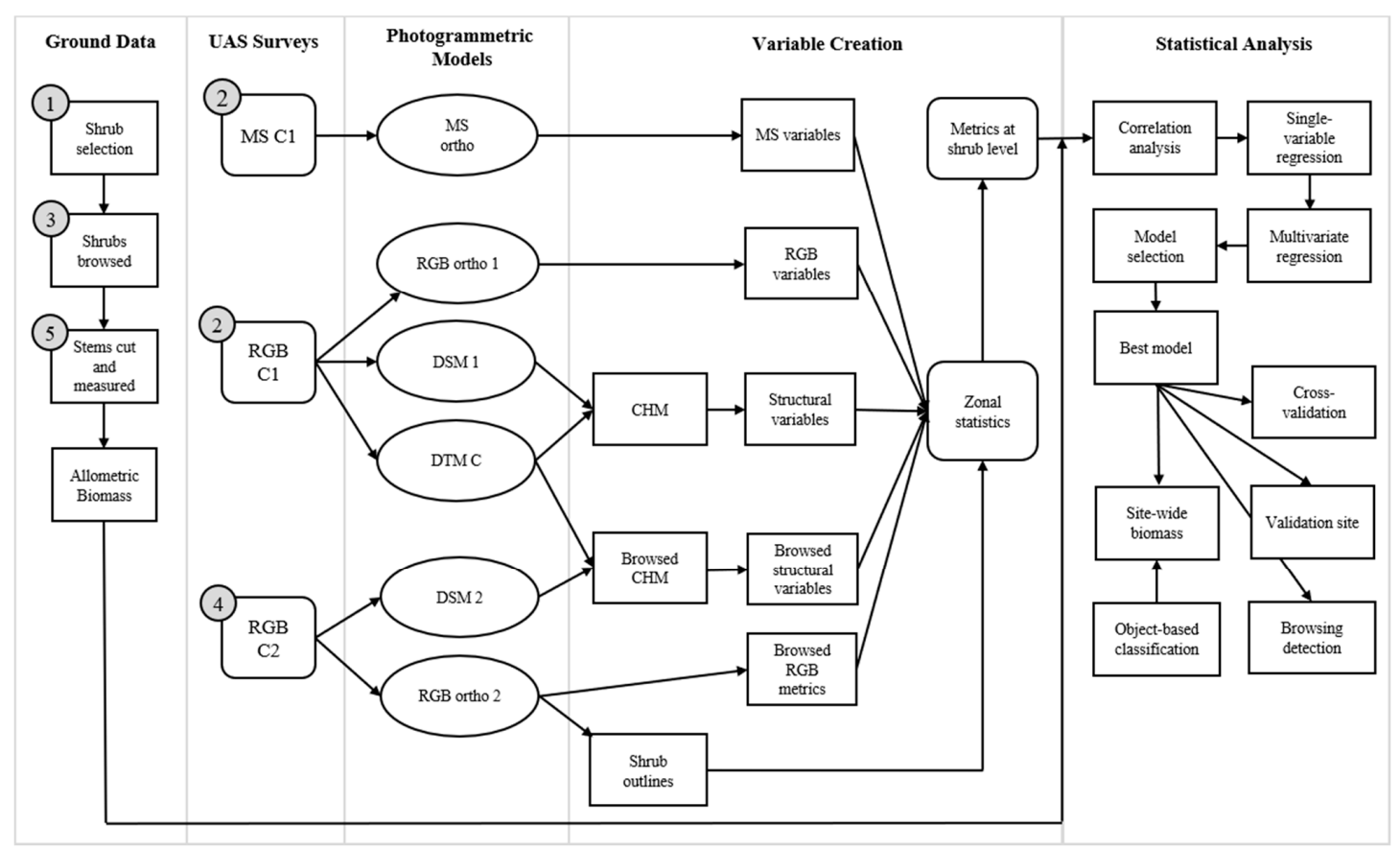

Figure 3. Data collection and analysis workflow for producing site-wide estimates of shrub aboveground biomass at the calibration site within Banff National Park, Alberta, Canada. Order of data collection steps (ground data and Unmanned Aerial System surveys) is indicated by numbers in grey circles. RGB = visible light; $M S$ = multispectral $; C H M=$ canopy height model; DSM = digital surface model; $\mathrm{DTM}=$ digital terrain model.

\subsection{UAS Surveys}

UAS surveys were conducted using the senseFly eBee fixed-wing UAS equipped with two different sensors. The S.O.D.A. sensor collects three-band RGB imagery with a resolution of 20 MP. The Sequoia four-band multispectral sensor simultaneously collects four images with 1.2 MP resolution using a rolling shutter in four wavelengths: green $(550 \pm 40 \mathrm{~nm})$, red $(660 \pm 40 \mathrm{~nm})$, red edge $(735 \pm 10 \mathrm{~nm})$, and near infrared $(790 \pm 40 \mathrm{~nm})$. The Sequoia includes a "sunshine sensor" to collect information on incoming solar irradiance used to correct imagery collected under different illumination conditions as well as a target used in post-processing to calibrate imagery to ambient lighting conditions [58].

Prior to each survey, nine ground control points (GCPs) were placed across the site. The markers were staked to the ground through the centre using magnetic survey pins to a height of five centimetres above the ground to ensure GCPs were placed at the exact same position each survey. At both sites, GCP placement followed the same pattern: one in the centre of the site, one each at $\sim 25 \mathrm{~m}$ from the centre GCP to the north, east, south, and west, and one each at $\sim 50 \mathrm{~m}$ from the centre GCP to the northeast, northwest, southeast, and southwest.

Survey flights were planned in the mission planning software eMotion 3 (senseFly, Cheseuax-sur-Laussane, Switzerland). Surveys were designed so that the UAS flew in a grid pattern over the site, flying a series of parallel transects and then another series of transects at a $90^{\circ}$ angle to the first set. Overlap between photos on the same transect was $70 \%$, and the overlap between photos on adjacent transects (sidelap) was $80 \%$, with a height above take off point of $70 \mathrm{~m}$ for all flights, resulting in an average ground sample distance (GSD) of $1.5 \mathrm{~cm}$ in the RGB imagery and $6 \mathrm{~cm}$ in the multispectral imagery. A total of six survey flights were conducted: three at the calibration site and three at the validation site (Table 1). Following the survey flights, we downloaded the aerial imagery and UAS flight logs and geotagged images using eMotion 3 with GPS locations recorded when each photo was taken by the UAS's autopilot. 
Table 1. Flight parameters of UAS surveys conducted at the calibration (C) and validation (V) sites in the shrub biomass estimation study area and digital terrain models (DTMs), digital surface models (DSMs), ground sample distance (GSD) and orthomosaics (Ortho) resulting from each flight.

\begin{tabular}{ccccccc}
\hline Site & Survey Flight & Date & GSD $(\mathbf{c m})$ & DTM & DSM & Ortho \\
\hline C & RGB C1 & $07 / 19 / 2018$ & 1.5 & DTM C & DSM1 & RGB Ortho C1 \\
& MS C1 & $07 / 19 / 2018$ & 6 & - & - & MS Ortho \\
& RGB C2 (shrubs “browsed") & $07 / 20 / 2018$ & 1.5 & - & DSM2 & RGB Ortho C2 \\
V & RGB V1 & $07 / 22 / 2018$ & 1.5 & DTM V & DSM V & RGB Ortho V \\
& RGB V2 (plots marked) & $07 / 22 / 2018$ & 1.5 & - & - & - \\
& MS V1 & $07 / 22 / 2018$ & 6 & - & - & MS Ortho V \\
\hline
\end{tabular}

\subsection{UAS Imagery Processing}

We processed images from the S.O.D.A. RGB sensor using Agisoft PhotoScan version 1.4. This software uses a structure from motion (SfM) algorithm to identify features appearing in multiple images and generate 3D models and orthomosaics from a series of overlapping photos [59,60].

Our workflow in PhotoScan to process each set of RGB images and produce photogrammetric point clouds and georeferenced orthomosaics was as follows: first, we filtered out low-quality photos by examining each photoset and deleting any photos that were extremely blurry or had very different illumination from other photos. Then, we used the Align Photos tool to find tie points common in images and create a sparse point cloud, followed by the Build Dense Cloud tool to create a dense 3D point cloud. Each point cloud was georeferenced using the ground-measured GPS coordinates of the nine ground control markers, and then, the Optimize Alignment tool was used to improve the sparse point cloud based on the identified coordinates. We used the Build Mesh tool to create a 3D mesh surface, the Build Texture tool to create a texture file for the surface, and the Build Orthomosaic tool to create a georeferenced seamless orthomosaic from each photoset and to export each orthomosaic. Lastly, a Digital Surface Model and a Digital Terrain Model were created by classifying ground points in the point cloud and using the Build DEM tool to export a surface both with all points (DSM) and excluding non-ground points and extrapolating the surface where points were excluded (DTM).

For the multispectral imagery, we used Pix4D version 4.5.2 for data processing and orthomosaic creation as we found its procedure for calibrating multispectral imagery produced superior results compared to PhotoScan. Prior to processing, we ensured each of the four bands were radiometrically calibrated using the built-in radiometric calibration workflow included in the Pix4D software for calibration of multispectral imagery from the Sequoia sensor. This workflow uses data from the camera's sunshine sensor and from the calibration target that was imaged prior to each survey in order to correct and calibrate the images' reflectance values according to the known values on the calibration target. Following this, the "Ag Multispectral" processing template from Pix4D's options was used to run the "Initial Processing" step using the default options in order to create a sparse point cloud. We used the rayCloud editor to georeference the point clouds using the GPS locations of the GCPs followed by the "Reoptimize" step to realign the sparse point cloud using the known GCP locations. Finally, we ran steps 2 (Point Cloud and Mesh) and 3 (DSM, Orthomosaic, and Index) using the default options to produce dense point clouds, DSMs, and orthomosaics for each of the four multispectral bands.

After all the RGB and multispectral datasets were processed, we used the high-resolution orthomosaics, which clearly showed shrub boundaries and flagging tape marking all measured shrubs in the study area, to manually delineate the outline of each measured shrub in ArcMap version 10.5 at the validation and calibration sites. 


\subsection{Structural and Spectral Variable Derivation}

We used an area-based approach to derive spectral and structural metrics at the level of each individual shrub. The area-based approach was chosen because our ground-based biomass data was collected at the scale of individual shrubs. Three different types of variables within the outline of each measured shrub were created: structural variables, representing attributes of the shrub related to height and canopy volume; spectral variables derived from the RGB imagery; and spectral variables derived from the multispectral imagery. We then calculated statistical metrics for each variable representing measures of central tendency, range, and variability of values within each measured shrub.

Using the digital surface and digital terrain models from our surveys (Table 1) we created canopy height models (CHMs) from which structural shrub attributes could be measured. First, we imported the DSMs, DTMs, and orthomosaics from each flight into ArcMap where they were displayed as raster imagery with each point having an $\mathrm{x}, \mathrm{y}$, and $\mathrm{z}$ value. With the Raster Math tool in ArcMap, we created a CHM by subtracting the values of the DTM from the values of the DSM at each point, resulting in another raster where each point has the same $x$ and $y$ values as the input rasters but a $z$ value representing the difference in height between the DSM and the DTM. We created two CHMs at the calibration site, one with shrubs un-browsed (DSM1 - DTM C) and one with shrubs browsed (DSM2 DTM C), and one CHM at the validation site (DSM V - DTM V). The un-browsed shrub CHM was used for most of the analysis at the calibration site, while the browsed shrub CHM was used only to examine whether changes in shrub AGB due to browsing could be detected. We then used the Zonal Statistics tool in ArcMap on each CHM to calculate maximum height, mean height, and shrub volume (the sum of all z-values within the shrub; Table 2).

Using the orthomosaics created from the RGB and multispectral imagery we derived a series of single-band metrics or multi-band vegetation indices (VIs) for each shrub. We reviewed existing studies using RGB and/or multispectral data derived from UAS imagery to estimate vegetation biomass to see which indices and wavelengths have previously been useful for this application and selected 28 RGB and 6 multispectral indices for their ability to accurately estimate shrub biomass (Table 2). For the single-band variables, we used Zonal Statistics as Table tool to calculate statistics for each of the four multispectral and three RGB bands within the outline of each measured shrub. For RGB and multispectral indices using two or more bands, we used the Image Analysis window in ArcGIS to calculate the index based on the formula found in the literature. We then used the Zonal Statistics as Table tool to calculate statistics on each index within the outlines of the measured shrubs. For all spectral variables, we calculated six basic descriptive statistics for each shrub: minimum value, maximum value, range, mean value, standard deviation, and sum of all values.

Table 2. All spectral and structural variables derived from RGB and multispectral UAS imagery that were calculated at the individual shrub level for relating to shrub biomass in this study.

\begin{tabular}{|c|c|c|c|c|}
\hline Type & Variable & Name & Formula $^{1}$ & Ref \\
\hline \multirow{3}{*}{ 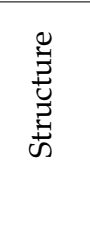 } & CHM.VOL & Canopy Height Model volume & $\begin{array}{l}\text { Sum of all height values } \\
\text { within each shrub }\end{array}$ & {$[36,61]$} \\
\hline & MAX_H & Maximum height & $\begin{array}{c}\text { Maximum height value within } \\
\text { the shrub }\end{array}$ & {$[61,62]$} \\
\hline & MEAN_H & Mean height & $\begin{array}{c}\text { Mean height value within the } \\
\text { shrub }\end{array}$ & {$[61,63]$} \\
\hline \multirow{5}{*}{ 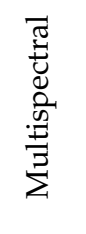 } & MSRED & Multispectral red band & Red band DNs & - \\
\hline & MSGREEN & Multispectral green band & Green band DNs & - \\
\hline & MSRE & Red edge band & Red edge band DNs & - \\
\hline & NIR & Near infrared band & Near infrared band DNs & - \\
\hline & NDVI & $\begin{array}{c}\text { Normalized difference vegetation } \\
\text { index }\end{array}$ & $(\mathrm{NIR}-\mathrm{R}) /(\mathrm{NIR}+\mathrm{R})$ & {$[46,64]$} \\
\hline
\end{tabular}


Table 2. Cont.

\begin{tabular}{|c|c|c|c|c|}
\hline Type & Variable & Name & Formula ${ }^{1}$ & Ref \\
\hline \multirow{29}{*}{ 岂 } & NDRE & Normalized difference red edge & $(\mathrm{NIR}-\mathrm{RE}) /(\mathrm{NIR}+\mathrm{RE})$ & {$[46,65]$} \\
\hline & BGRI & Blue green ratio index & $\mathrm{B} / \mathrm{G}$ & [66] \\
\hline & BLUE & Blue band & Blue band DNs & {$[61]$} \\
\hline & BRATIO & Blue ratio & $\mathrm{B} /(\mathrm{R}+\mathrm{G}+\mathrm{B})$ & [61] \\
\hline & BRRI & Blue red ratio index & $\mathrm{B} / \mathrm{R}$ & [66] \\
\hline & CIVE & Colour index of vegetation & $\begin{array}{c}0.441 \times \mathrm{R}-0.881 \times \mathrm{G}+0.385 \\
\times \mathrm{B}+18.78745\end{array}$ & {$[61,67]$} \\
\hline & ExB & Excess blue index & $1.4 \times$ blue ratio - red ratio & [61] \\
\hline & ExG & Excess green index & $\begin{array}{c}2 \times \text { green ratio }- \text { red ratio }- \\
\text { blue ratio }\end{array}$ & [61] \\
\hline & ExGR & Excess green red index & ExG - ExR & [61] \\
\hline & ExR & Excess red index & $1.4 \times$ blue ratio - green ratio & [61] \\
\hline & GBRI & Green blue ratio index & $\mathrm{G} / \mathrm{B}$ & [61] \\
\hline & GRATIO & Green Ratio & $G /(R+G+B)$ & [61] \\
\hline & GREEN & Green band & Green band DNs & [61] \\
\hline & GRRI & Green red ratio index & $\mathrm{G} / \mathrm{R}$ & {$[61]$} \\
\hline & IKAW & Kawashima index & $(\mathrm{R}-\mathrm{B}) /(\mathrm{R}+\mathrm{B})$ & {$[61,68]$} \\
\hline & INT & Colour intensity index & $(R+G+B) / 3$ & [61] \\
\hline & MGRVI & $\begin{array}{c}\text { Modified green red vegetation } \\
\text { index }\end{array}$ & $(\mathrm{G} 2-\mathrm{R} 2) /(\mathrm{G} 2+\mathrm{R} 2)$ & [36] \\
\hline & MVARI & Modified VARI & $(G-B) /(G+R-B)$ & [32] \\
\hline & NGBI & Normalized green blue index & $(G-B) /(G+B)$ & [30] \\
\hline & NGRDI & $\begin{array}{l}\text { Normalized green red difference } \\
\text { index }\end{array}$ & $(G-R) /(G+R)$ & {$[30]$} \\
\hline & RBRI & Red blue ratio index & $\mathrm{R} / \mathrm{B}$ & [61] \\
\hline & RED & Red band & Red band DNs & [61] \\
\hline & RGBVI & Red green blue vegetation index & $\mathrm{G} 2-(\mathrm{B} \times \mathrm{R}) / \mathrm{G} 2+(\mathrm{B} \times \mathrm{R})$ & [36] \\
\hline & RGRI & Red green ratio index & $\mathrm{R} / \mathrm{G}$ & [66] \\
\hline & RRATIO & Red ratio & $R /(R+G+B)$ & [61] \\
\hline & TGI & Triangular greenness index & $G-(0.39 \times R)-(0.61 \times B)$ & {$[30,69]$} \\
\hline & VARI & $\begin{array}{l}\text { Visible atmospherically resistant } \\
\text { index }\end{array}$ & $(G-R) /(G+R-B)$ & {$[32,70]$} \\
\hline & VDVI & $\begin{array}{l}\text { Visible band difference vegetation } \\
\text { index }\end{array}$ & $(2 \times G-R-B) /(2 \times G+R+B)$ & {$[32]$} \\
\hline & WI & Woebbecke index & $(G-B) /(G+R)$ & [61] \\
\hline
\end{tabular}

${ }^{1} \mathrm{R}$ = red band; $\mathrm{G}$ = green band; $\mathrm{B}=$ blue band; $\mathrm{NIR}$ = near-infrared band; $\mathrm{RE}$ = red-edge band; $\mathrm{DN}$ = digital number.

\subsection{Shrub Biomass Model Creation and Selection}

We conducted the following statistical analyses in SPSS version 26 (IBM, Armonk, NY, USA). Using a stepwise approach, we derived a candidate set of single- and multiple-variable linear regressions using a stepwise approach to ensure only significant variables were retained in models. First, we conducted a single-variable linear regression analysis using each of the metrics as the predictor variable and allometric biomass as the dependent variable. Then, a set of models with two predictor variables was created by combining two variables at a time, and it was evaluated whether model fit was improved over single-variable models. Lastly, we tested whether adding in a third variable, again selected from the top single-variable models, to the best two-variable models could improve performance. Correlations among all predictor variables were assessed prior to model building (Appendix A, Table A1), and variance inflation factor (VIF) values between predictor variables were examined in regression model outputs. Variables with correlations $>0.50$ or VIF values $>2$ were not included in the same model to avoid issues of collinearity in regression models, which can affect the slope and/or significance of predictor parameter estimates [71].

Several methods were used to assess model fit to determine which combination of the derived parameters most accurately estimated shrub biomass in the best models containing uncorrelated 
predictor variables. We compared the coefficient of determination $\left(\mathrm{R}^{2}\right)$ statistic for each model. We also used the Akaike's information criterion (AIC) approach to model selection. AIC is useful for finding the most parsimonious model that best fits the data within an a priori candidate set of models [72]. Since our sample size was small (60), the number of parameters in each model divided by the number of samples (n/K) was less than 40 , so we used the corrected AIC statistic (AICc) for small sample sizes, with lower values indicating better model fit to the data as compared to other models in that candidate set [72]. We compared the $\Delta \mathrm{i}$ values for each model, which indicate the increase in AICc value of each model compared to the model with the lowest AICc, and the model weight, which indicates the strength of support for that model being the most appropriate among the candidate set of models. Lastly, we looked at the standard error (SE) and significance for predictor variable parameter estimates, excluding models that did not have significance ( $p$-value $>0.05$ or parameter estimate confidence interval overlapping zero) in at least $50 \%$ of the predictor variables from the AIC model selection.

\subsection{Shrub Biomass Model Validation}

We applied each of the selected models developed at the calibration site to predict biomass of shrubs at the validation site to evaluate how well each model performed at a geographically distinct location from the training site. We used the parameter estimates from each top model equation to estimate biomass for each of the 15 Betula and 15 Salix shrubs measured at the validation site, then conducted a linear regression between the predicted and the observed biomass for each shrub.

We used the coefficient of determination values from the linear regressions using UAS-derived biomass to predict allometric biomass to assess validation model performance and compared the root mean square error (RMSE) and mean absolute error (MAE) statistics averaged across the testing folds of each model, with lower values of these two statistics indicating less difference between predicted and observed biomass. We also calculated the mean bias error (MBE) for the validation site biomass estimates, where values close to zero indicate no bias in predicted biomass, positive values indicate biomass is overestimated on average, and negative values indicate biomass is underestimated.

\subsection{Mapping Shrub Biomass Across the Study Area}

In order to estimate site-wide shrub biomass, we classified the study area using the rule-based, object-oriented feature extraction tool in the software ENVI version 5.5 (L3Harris, Melbourne, FL, USA). We applied our classification using three raster images as input data that we found were most useful for distinguishing between shrub and non-shrub objects: the CHM, the BGRI vegetation index, and the red ratio vegetation index. Following segmentation, we defined rules for three classes: shrubs, grass, and other, which included dead trees, small rocks, and gravel. The result of the classification was a shapefile with the boundaries of each of the three classes, which we imported into ArcGIS version 10.7 (ESRI, Redlands, CA, USA).

To assess classification accuracy, we generated 200 points distributed randomly across the image and visually determined the true class and rule-based class each point fell within. We then used a confusion matrix to calculate errors of omission and commission and producer's and user's accuracy for each class (Appendix B, Table A2). Out of the 200 random points generated, 193 were assigned to the correct class, giving a total accuracy of 0.965 . The shrub class had a producer's accuracy of 0.99 and a user's accuracy of 0.97 with slightly more errors of commission than omission.

We created a $1 \times 1$-m grid covering the classified shrub area to display shrub biomass at a fine scale. Then, we extracted the total sum of VI and CHM values in each grid cell across the shrub class, applied the equations derived from our top models, using the VI and CHM values as predictor variables in the model to estimate shrub biomass in each shrub class grid cell, and summed all shrub class biomass values to determine site-wide shrub biomass predicted by the model. 


\section{Results}

\subsection{Ground-Measured Biomass}

We applied the general shrub allometric equation to each of the 30 Betula and 30 Salix genus shrubs at the calibration site to get ground-measured estimates of biomass (Table 3). Salix shrubs had on average more individual stems with slightly larger mean BSD than Betula shrubs, leading to higher mean AGB of Salix compared to Betula (Table 3).

Table 3. Ground-based measurements of leaf, twig, and total aboveground biomass (in grams) of Betula and Salix shrubs at the calibration site derived from a general shrub allometric equation. BSD = basal stem diameter.

\begin{tabular}{cccccccc}
\hline $\begin{array}{c}\text { Genus (\# } \\
\text { Samples) }\end{array}$ & $\begin{array}{c}\text { Mean \# } \\
\text { Stems }\end{array}$ & $\begin{array}{c}\text { Mean } \\
\text { Stem BSD } \\
(\mathbf{m m})\end{array}$ & $\begin{array}{c}\text { Mean } \\
\text { Total AGB } \\
\mathbf{( g )}\end{array}$ & $\begin{array}{c}\text { Mean } \\
\text { Total Twig } \\
\text { Biomass }\end{array}$ & $\begin{array}{c}\text { Mean } \\
\text { Total Leaf } \\
\text { Biomass }\end{array}$ & $\begin{array}{c}\text { Mean } \\
\text { Twig } \\
\text { Biomass }\end{array}$ & $\begin{array}{c}\text { Mean Leaf } \\
\text { Biomass }\end{array}$ \\
\hline All (60) & 75.02 & 8.36 & 2966.36 & 1900.08 & 1066.29 & 25.85 & 14.22 \\
Betula (30) & 56.60 & 8.24 & 2160.76 & 1395.51 & 765.24 & 25.62 & 14.10 \\
Salix (30) & 93.43 & 8.48 & 3771.97 & 2404.64 & 1367.34 & 26.07 & 14.33 \\
\hline
\end{tabular}

\subsection{Spectral and Structural Metric Comparison}

The results of our correlation analysis between each of the six descriptive metrics (mean, range, minimum, maximum, standard deviation, and sum) derived from each of the 34 spectral bands and indices, plus the three structural metrics (volume, mean height, and maximum height), indicated that the sum metrics had the strongest correlations with allometric AGB. Twenty of the range metrics had correlations with biomass greater than 0.60 , as did nine of the minimum metrics and 12 of the maximum metrics. None of the mean or standard deviation metrics had a correlation greater than 0.51 (mean) or 0.59 (standard deviation) with biomass.

In single-variable linear regression models, sum metrics had the highest $\mathrm{R}^{2}$ values among the four metric types, with values ranging from 0.75 for CHM volume to 0.89 for the RGB VI red ratio. Conversely, regression coefficients between the range, minimum, and maximum metrics and allometric biomass were much lower, with an average $\mathrm{R}^{2}$ of $0.45,0.48$., and 0.46 for each of the three metrics, respectively. The sum of spectral or structural variable values within the area of a shrub had a much stronger relationship with allometric AGB than any other metric we tested. A summary of Pearson correlation coefficients $(r)$ and linear regression coefficients of determination $\left(R^{2}\right)$ for all variables is included in Table A1 in Appendix A.

\subsection{Model Selection}

Using our stepwise model creation procedure, we combined variables from the top single-variable models to create a set of two-variable models. The sum metrics had the most explanatory power for modelling shrub AGB in single-variable models. Ratio-based RGB VIs, particularly the red ratio and green ratio, had the best performance when combined with MS metrics into two-variable models. Due to high correlations among many of the RGB variables, there were no two-variable models that contained two RGB VI or two MS VI metrics that met our model selection criteria.

After exploring combinations of two variables in models and eliminating those that did not fit our criteria (i.e., collinearity between predictors, insignificance in parameter estimates), we were left with six two-variable models in the candidate set. As a final model creation step, we evaluated whether adding another variable to the top two-variable models could improve model performance but found that this always resulted in loss of significance of parameter estimates in the model compared to the one- or two-variable models, with the exception of adding the mean of RGB green values and the standard deviation of MS red values to the sum of the red ratio index. We included the top RGB VI metric (red ratio sum), top MS metric (NDRE sum), and the top structural metric (CHM volume) 
single-variable models in the candidate set to evaluate their performance compared to the two- and three-variable models. Therefore, our final top model set included ten models: one three-variable model, six two-variable models, and three single-variable models.

AIC model selection revealed that two models, green ratio sum + MS red max and red ratio sum + MS red STD, had the best fit to the data as evidenced by the lowest AICc values and highest model weights out of the candidate set of models (Table 4). However, five other models had $\Delta \mathrm{i}$ values within two points of the best model, indicating substantial support for these models [72], and the top single-variable model (sum of the red ratio VI) had a $\Delta \mathrm{i}$ of $<3.0$, also very close to the best model in the candidate set.

Table 4. Results of Akaike's information criterion (AIC) model selection on the top shrub AGB estimation models. Model weight is calculated from this set of models. AICc $=$ AIC corrected for small sample size; $\Delta \mathrm{i}=$ change in AIC points from top model; $\mathrm{SE}=$ standard error; sig = p-level significance.

\begin{tabular}{|c|c|c|c|c|c|c|c|}
\hline Model & $\mathrm{AICc}$ & $\Delta \mathbf{i}$ & Weight & Parameter & $\beta$ & SE & Sig \\
\hline \multirow{3}{*}{$\begin{array}{l}\text { GREENRATIO.SUM + } \\
\text { MSRED.MAX }\end{array}$} & \multirow[t]{3}{*}{807.64} & \multirow[t]{3}{*}{0.00} & \multirow[t]{3}{*}{0.18} & Constant & 3595.88 & 1411.43 & 0.01 \\
\hline & & & & GREENRATIO.SUM & 0.93 & 0.04 & 0.00 \\
\hline & & & & MSRED.MAX & -0.09 & 0.04 & 0.01 \\
\hline \multirow{3}{*}{$\begin{array}{l}\text { REDRATIO.SUM + } \\
\text { MSRED.STD }\end{array}$} & \multirow[t]{3}{*}{807.64} & \multirow[t]{3}{*}{0.00} & \multirow[t]{3}{*}{0.18} & Constant & 981.66 & 469.24 & 0.04 \\
\hline & & & & REDRATIO.SUM & 1.10 & 0.05 & 0.00 \\
\hline & & & & MSRED.STD & -0.27 & 0.12 & 0.03 \\
\hline \multirow{3}{*}{$\begin{array}{l}\text { GREENRATIO.SUM + } \\
\text { NIR.MAX }\end{array}$} & \multirow[t]{3}{*}{808.08} & \multirow[t]{3}{*}{0.43} & \multirow[t]{3}{*}{0.15} & Constant & 3411.58 & 1388.77 & 0.02 \\
\hline & & & & NIR.MAX & -0.10 & 0.04 & 0.02 \\
\hline & & & & GREENRATIO.SUM & 0.93 & 0.04 & 0.00 \\
\hline \multirow{4}{*}{$\begin{array}{l}\text { REDRATIO.SUM + } \\
\text { GREEN.MEAN + } \\
\text { MSRED.STD }\end{array}$} & \multirow[t]{4}{*}{808.44} & \multirow[t]{4}{*}{0.80} & \multirow[t]{4}{*}{0.12} & Constant & 3246.42 & 1894.66 & 0.09 \\
\hline & & & & REDRATIO.SUM & 1.08 & 0.05 & 0.00 \\
\hline & & & & GREEN.MEAN & -15.41 & 12.49 & 0.22 \\
\hline & & & & MSRED.STD & -0.25 & 0.12 & 0.04 \\
\hline \multirow{3}{*}{$\begin{array}{l}\text { REDRATIO.SUM + } \\
\text { MSRED.MAX }\end{array}$} & \multirow[t]{3}{*}{808.51} & \multirow[t]{3}{*}{0.87} & \multirow[t]{3}{*}{0.12} & Constant & 2863.32 & 1409.01 & 0.05 \\
\hline & & & & MSRED.MAX & -0.07 & 0.04 & 0.05 \\
\hline & & & & REDRATIO.SUM & 1.10 & 0.05 & 0.00 \\
\hline \multirow{3}{*}{$\begin{array}{l}\text { GREENRATIO.SUM + } \\
\text { MSRED.STD }\end{array}$} & \multirow[t]{3}{*}{808.59} & \multirow[t]{3}{*}{0.94} & \multirow[t]{3}{*}{0.12} & Constant & 1071.83 & 473.35 & 0.03 \\
\hline & & & & GREENRATIO.SUM & 0.92 & 0.04 & 0.00 \\
\hline & & & & MSRED.STD & -0.29 & 0.12 & 0.02 \\
\hline \multirow{3}{*}{$\begin{array}{l}\text { REDRATIO.SUM + } \\
\text { NIR.MAX }\end{array}$} & \multirow[t]{3}{*}{809.33} & \multirow[t]{3}{*}{1.68} & \multirow[t]{3}{*}{0.08} & Constant & 2526.58 & 1388.25 & 0.07 \\
\hline & & & & REDRATIO.SUM & 1.10 & 0.05 & 0.00 \\
\hline & & & & NIR.MAX & -0.08 & 0.04 & 0.07 \\
\hline \multirow{2}{*}{ REDRATIO.SUM } & \multirow{2}{*}{810.49} & \multirow[t]{2}{*}{2.84} & 0.04 & Constant & -6.81 & 172.55 & 0.97 \\
\hline & & & & REDRATIO.SUM & 1.06 & 0.05 & 0.00 \\
\hline & 816.70 & 9.06 & 0.00 & Constant & 41.61 & 177.82 & 0.82 \\
\hline NDRE. & & & & NDRE.SUM & 61.739 & 2.976 & 0.00 \\
\hline CHM.VOL & 859.99 & 52.4 & 0.00 & Constant & 940.92 & 219.85 & 0.00 \\
\hline & & & & CHM.VOL & 2.96 & 0.22 & 0.00 \\
\hline
\end{tabular}

\subsection{Model Validation}

We applied the parameter estimates for each model developed at the calibration site to estimate shrub AGB from spectral and structural information at the validation site in linear regression models. Calibration site $\mathrm{R}^{2}$ ranged from 0.746 for the $\mathrm{CHM}$ volume model to 0.896 for the red ratio sum + green mean + MS red standard deviation model. RMSE as a percentage of mean total allometric AGB at the calibration site (from all shrubs measured at the site) ranged from 27 to $42 \%$ (Table 5). Observed versus predicted values from each model showed a strong linear relationship at the calibration and validation sites; this relationship is visualized for one of the two top models (red ratio sum + MS red standard deviation) from the AIC model selection at both sites in Appendix C (Figure A1).

Validation site $\mathrm{R}^{2}$ ranged from 0.732 for the $\mathrm{CHM}$ volume model to 0.773 for the model with three variables (Table 5). Validation site RMSE as a percentage of mean total allometric AGB ranged 
from 44 to $100 \%$ and was highest for the green ratio sum + MS red max model and lowest for the NDRE model. Validation site MAE as a percentage of mean total allometric AGB ranged from $32 \%$ (NDRE model) to $86 \%$ (green ratio sum + MS red max model). Validation site MBE was always positive and was highest for the green ratio sum + MS red max model and lowest for the CHM volume model. The two models containing the NIR max variable had the lowest MBE, RMSE\%, and MAE\% out of the multivariate models.

\subsection{Total Site-Wide Shrub Aboveground Biomass}

Using the classified shrub area, which covered 10,753 square metres of the study area, we extracted the total sum of values for the parameters from the top model as indicated by AIC model selection (red ratio sum + MS red standard deviation) and used the equation from the linear regression with allometric AGB to estimate total shrub AGB across the site. Total shrub AGB from the best model was $17,600 \mathrm{kgs}$, with an average of $1.64 \mathrm{kgs}$ of shrub biomass per square metre of shrub-covered area and an average of $0.66 \mathrm{kgs} / \mathrm{m}^{2}$ across the entire study area. The spatial distribution of shrub AGB across the study site is shown in Figure 4.

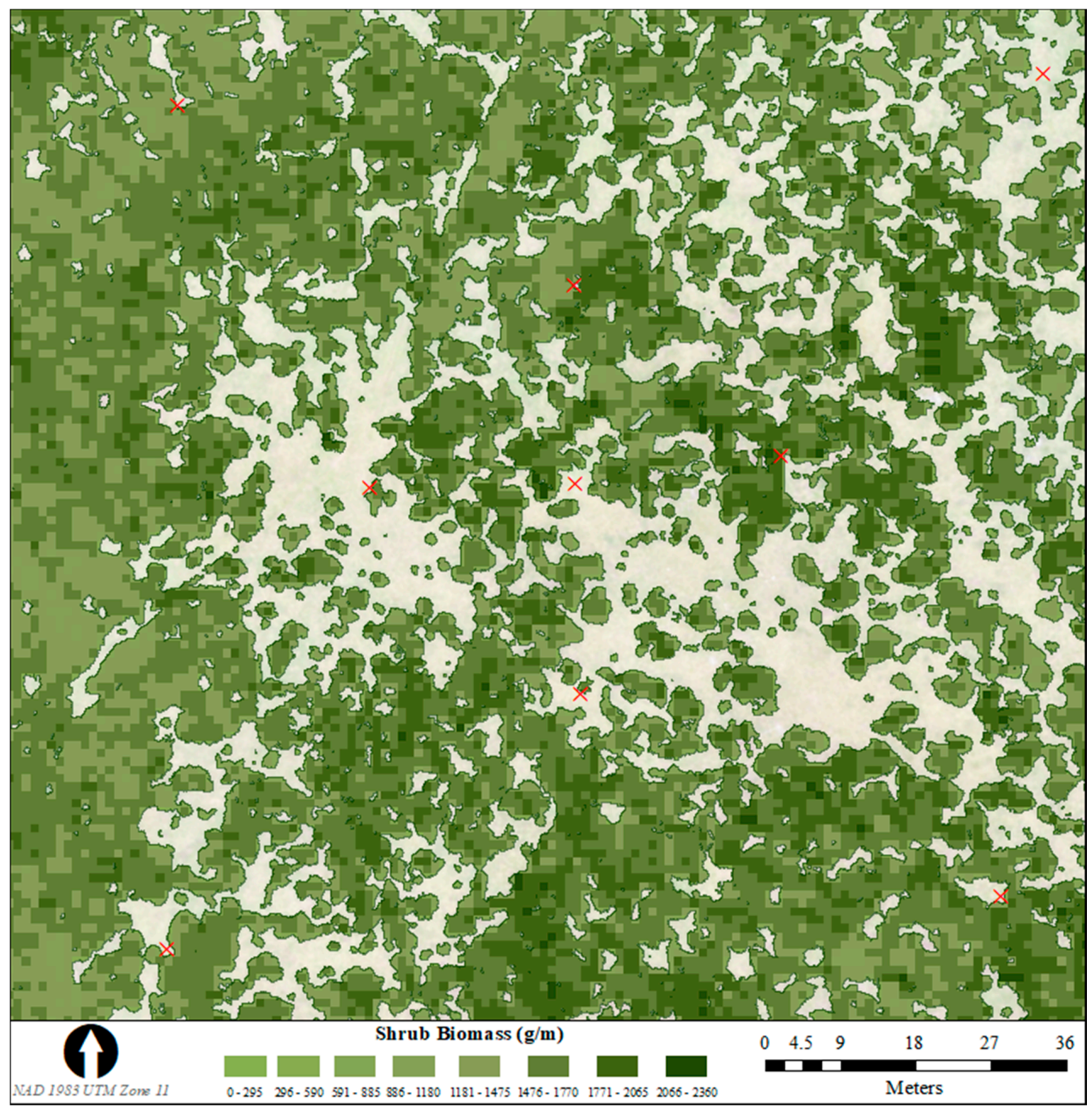

Figure 4. Grams of shrub aboveground biomass per square metre of classified shrub area across the calibration site covered using UAS surveys in Banff National Park, Alberta, Canada. Red crosses show the locations of the ground control points across the study site. The white area represents non-shrub classes (grass or bare ground). 
Table 5. Calibration site model coefficients of determination $\left(R^{2}\right)$ and root mean square error (RMSE) and validation results ( ${ }^{2}$, RMSE, mean absolute error (MAE), mean bias error (MBE)) from a linear regression of predicted shrub aboveground biomass with allometric shrub aboveground biomass at the validation site, calculated using parameter estimates from best calibration models.

\begin{tabular}{|c|c|c|c|c|c|c|c|c|c|}
\hline \multirow{2}{*}{ Model } & \multicolumn{3}{|c|}{ Calibration Site } & \multicolumn{6}{|c|}{ Validation Site } \\
\hline & $\mathbf{R}^{2}$ & RMSE (g) & RMSE \% & $\mathbf{R}^{2}$ & RMSE (g) & RMSE \% & MAE (g) & MAE $\%$ & MBE (g) \\
\hline $\begin{array}{l}\text { GREENRATIO SUM } \\
+ \text { MSRED MAX }\end{array}$ & 0.895 & 798.95 & $27 \%$ & 0.762 & 2525.5 & $100 \%$ & 2161.3 & $86 \%$ & 2072.6 \\
\hline $\begin{array}{l}\text { REDRATIO SUM + } \\
\text { MSRED STD }\end{array}$ & 0.895 & 799.08 & $27 \%$ & 0.756 & 1935.0 & $77 \%$ & 1516.1 & $60 \%$ & 1212.1 \\
\hline $\begin{array}{l}\text { GREENRATIO SUM } \\
+ \text { NIR MAX }\end{array}$ & 0.894 & 801.83 & $27 \%$ & 0.768 & 1266.0 & $50 \%$ & 899.5 & $36 \%$ & 108.2 \\
\hline $\begin{array}{l}\text { REDRATIO SUM + } \\
\text { GREEN MEAN + } \\
\text { MSRED STD }\end{array}$ & 0.896 & 795.45 & $27 \%$ & 0.773 & 2033.0 & $81 \%$ & 1617.8 & $64 \%$ & 1409.0 \\
\hline $\begin{array}{l}\text { REDRATIO SUM + } \\
\text { MSRED MAX }\end{array}$ & 0.894 & 804.74 & $27 \%$ & 0.752 & 2464.3 & $98 \%$ & 2091.9 & $83 \%$ & 1964.2 \\
\hline $\begin{array}{l}\text { GREENRATIO SUM } \\
+ \text { MSRED STD }\end{array}$ & 0.894 & 805.25 & $28 \%$ & 0.773 & 1784.9 & $71 \%$ & 1398.0 & $56 \%$ & 1073.2 \\
\hline $\begin{array}{l}\text { REDRATIO SUM + } \\
\text { NIR MAX }\end{array}$ & 0.892 & 810.24 & $28 \%$ & 0.750 & 1441.6 & $57 \%$ & 1042.8 & $41 \%$ & 450.6 \\
\hline REDRATIO SUM & 0.888 & 826.69 & $28 \%$ & 0.756 & 1731.80 & $69 \%$ & 1344.30 & $53 \%$ & 1016.4 \\
\hline NDRE SUM & 0.876 & 870.63 & $30 \%$ & 0.758 & 1096.00 & $44 \%$ & 807.6 & $32 \%$ & 207.8 \\
\hline CHM SUM & 0.746 & 1248.87 & $43 \%$ & 0.732 & 1183.00 & $47 \%$ & 821 & $33 \%$ & 31.0 \\
\hline
\end{tabular}




\section{Discussion}

\subsection{Accumulated Vegetation Index}

Our analysis revealed that the aboveground biomass of shrubs in the Betula and Salix genera could accurately be modelled at a high spatial resolution using metrics derived from UAS imagery. The workflow developed in our study provides a way to estimate site-wide shrub AGB at a broader spatial scale than ground-based measurements and with a higher resolution than satellite imagery. We found that metrics using the sum of all VI values within each shrub outline, rather than measures of central tendency or deviation as are commonly used, had a superior performance over both CHM-based structural data and other spectral metrics. These "accumulated VIs" contain structural information about shrub canopy roughness and size in addition to spectral data [61], capturing both spatial and spectral variations in shrub AGB within a single parsimonious metric. To our knowledge, other UAS-derived accumulated VI metrics for AGB estimation have not been described previously in the literature, although one study found that an RGB VI weighted by canopy volume was the best variable for estimating soybean crop AGB [61].

In our study area dominated by shrubs with a low height $(<2 \mathrm{~m})$, the area-based VI accumulation approach was more useful for relating to shrub biomass than three-dimensional metrics such as height or volume, with accumulated VI metrics out-performing structural variables in single-variable models and showing a very strong linear relationship to ground-measured biomass. Shrub area alone (in metres squared) showed a high correlation $(\mathrm{r}=0.88)$ and coefficient of determination $\left(\mathrm{R}^{2}=0.824\right)$ with allometric shrub biomass, but the accumulated VI improved upon these values by including spectral as well as areal information. The accumulated VI appears to be ideal for AGB estimation for low-stature vegetation such as shrubs, fusing spectral and structural information into one metric with the advantage of not needing to create a CHM, which increases the amount of effort and uncertainty in biomass estimates. The low height of shrubs in our study area means that even small errors in a CHM could lead to biased estimates of shrub structure, affecting the ability of structural metrics to accurately predict biomass.

Model performance could be improved slightly over single-variable linear regressions by combining multiple uncorrelated metrics into one multiple regression model. For example, the two top models in the AIC selection contained two metrics - an accumulated ratio-based RGB VI and an MS metric using the red wavelength — and had the highest $R^{2}$ and lowest RMSE values of the tested models at the calibration site. Other UAS-based biomass studies also found that combining multiple data types into parametric or non-parametric regression models improved performance over single-variable models for various vegetation types [28,32,44,73]. Another found that shrub biomass could be modelled better by combining LiDAR-based height measurements with aerial imagery spectral data compared to LiDAR or aerial imagery alone [22].

However, in our study the $\Delta \mathrm{i}$ value of $<3$ from the top model to the single variable accumulated red ratio model in the AIC model selection is only slightly over the AIC rule of thumb that models within two points of the best model have substantial support and a similar ability to explain variation in the data as the best model in the candidate set [72]. This represents a marginal improvement in accuracy for the top model that requires deriving both MS and RGB variables, which increases effort of data collection by requiring multiple survey flights compared to the single-variable RGB VI sum models which are derived from a single RGB survey. Additionally, when applied to the validation site, the models with two or three predictor variables tended to have higher RMSE and/or MAE compared to the single-predictor variables, with the exception of models combining an RGB ratio-based sum metric with a NIR metric, which had a more stable performance in validation.

For the purposes of fine-scale site-wide shrub AGB estimation, we believe a parsimonious single-variable linear regression model containing the accumulated red ratio VI using data that can be collected from a single UAS survey is preferable over the slight increase in accuracy but concurrent increase in effort and uncertainty that would come from combining metrics from two different sensors 
for a multiple regression model. The accumulated VI metric provides a straightforward approach for shrub AGB estimation since data collection requires only a single UAS survey during peak vegetation greenness, which is ideal for streamlining workflows for management and monitoring of vegetation within a large national park such as Banff. We would be interested in investigating whether the sum of all VI values across the vegetated area relates similarly strongly to the biomass of other plant species or whether the biophysical characteristics of low-stature woody shrubs makes them the ideal vegetation type for this methodology.

\subsection{Spectral Metric Comparison}

RGB-based spectral metrics and VIs outperformed multispectral metrics for shrub biomass estimation in this study. Vegetation characterization with spectral information often uses non-visible wavelengths of electromagnetic radiation [74], especially indices that use the near infrared or red edge region of the electromagnetic spectrum. However, despite being limited to visible wavelengths of light, RGB VIs can also be sensitive to biophysical characteristics of vegetation [32,75], and other researchers using UAS data to estimate vegetation biomass found that RGB VIs could outperform multispectral or hyperspectral VIs $[32,36,66,76,77]$. Due to high correlations among the RGB and the MS variables, combining multiple RGB or multiple MS metrics in the same model did not improve model performance. Combining both RGB and MS metrics in the same model slightly increased accuracy over single-variable models, but this method requires conducting a survey with each sensor which increases data collection and processing effort.

Compared to the multispectral data, the smaller ground sampling distance of the RGB imagery collected in this study resulted in a higher spatial resolution $(\sim 1.5 \mathrm{~cm}$ pixels in RGB data, $\sim 6 \mathrm{~cm}$ pixels in multispectral data). This means each individual shrub contained more pixels for use in analysis. The lower resolution of the multispectral imagery also meant that accurate classification of shrubs from these data is challenging, likely requiring the collection of RGB information to ensure accurate delineation of vegetation for applying site-wide biomass prediction models. Conducting a single UAS survey to collect RGB data that can be used for image classification and biomass estimation provides a logistically simpler process than collecting both types of imagery.

We found that the ratio-based RGB VIs were particularly useful for biomass estimation. Red ratio and green ratio both performed well in single-variable models, and both retained good performance when included in additive models an MS VI metric. This result was similar to another study using UAS data which found that the red ratio from RGB imagery was the best index for predicting winter wheat biomass among the RGB VIs tested [66]. Ratio-based RGB VIs may be less sensitive to changes in illumination and atmospheric conditions over time compared to other VIs, making them more robust when conditions vary during data collection [61].

Out of the multispectral bands and VIs tested, the model containing the NDRE variable performed the best for biomass prediction and had a more stable performance when applied at the validation site compared to the RGB VIs. This is likely because the multispectral data was radiometrically corrected. Red-edge indices have a strong relationship with leaf biomass and weaker relationship with stem biomass [10,23] and are sensitive to canopy structure [70], making them useful for AGB estimation for vegetation species with large leaves or for growth stages of plants when the canopy is dominated by leaves. Red edge indices may also be slightly less prone to saturation than those using the NIR band [18], and we found that NDRE outperformed the NIR band or NDVI alone. However, the two models that included a metric derived from the NIR band with a ratio-based RGB VI had lower MBE, MAE, and RMSE when applied to the validation site than other two-variable models. The NIR band may be useful in conjunction with RGB information for increasing the stability of models applied at other locations although including it in models with RGB VIs requires data collection with two different sensors. 


\subsection{Structural Metric Comparison}

Out of the structural metrics tested, shrub volume demonstrated a greater ability than mean or maximum height to predict the aboveground biomass of individual shrubs, with coefficients of determination of $\sim 0.75$ with ground-based biomass in calibration models and $\sim 0.73$ in validation, although these values were lower than those of the RGB and multispectral models. Canopy volume calculated from UAS imagery was found to have a good ability to predict aboveground biomass of Arctic shrubs [9], as well as of other vegetation including boreal forest trees [31], onion plants [39], and soybean crops [61]. Compared to height metrics alone, volume metrics capture variation in vegetation height and density simultaneously [39], characterizing canopy structure traits in both vertical and horizontal dimensions [61].

We found similar or higher accuracy in the ability to model shrub AGB from volume compared to height, as did studies using LiDAR-based height metrics [10,21,78,79]. Conversely, studies using shrub volume derived from terrestrial laser scanning found stronger positive relationships to aboveground shrub biomass, with $\mathrm{R}^{2}$ values $>0.85[16,80,81]$, demonstrating that volume metrics may relate more strongly to shrub biomass than height metrics alone $[10,21,22,78]$. UAS-derived point clouds usually have a very high point density closer to terrestrial than to aerial laser scanning, but laser scanning has a greater ability to penetrate through vegetation to the terrain, which may explain why terrestrial laser scanning-based shrub biomass estimates using volume had higher coefficients of determination than those found in this study.

There is likely to be greater uncertainty and more error in vegetation volume estimates from UAS CHM models compared to terrestrial laser scanning due to the difficulty of accurately characterizing the terrain beneath dense vegetation in UAS imagery. Over- or underestimation of local terrain variations and misclassification of terrain as vegetation or vice versa can lead to biased estimates of structural metrics and biomass compared to field measurements [31]. Several studies using UAS data to estimate deciduous and coniferous tree biomass found that tree height from a CHM was underestimated compared to field measurements $[41,43,62,63]$. We found that shrub biomass was approximately equally over- and underestimated by $\mathrm{CHM}$ volume, although the biomass of smaller shrubs was more often overestimated and larger shrubs more often underestimated, a pattern found by other UAS-based vegetation biomass studies $[44,73,75,82]$.

\subsection{Site-Wide Aboveground Biomass}

An important finding in this study was the linear relationship between our predictor variables and shrub AGB, which means that classification of shrubs in order to apply the AGB prediction equation is not necessary to the individual plant level, even though our equations were derived for individual plants. Rather, the area covered by shrubs is all that is needed, over which the total sum of RGB VI values can be calculated and used in the equation to linearly predict total shrub AGB across the shrub class. This result is similar to that found by the existing published study using UAS data to estimate shrub AGB [9] as well as to studies using terrestrial LiDAR to quantify aboveground biomass of sagebrush shrubs [10], which also reported a linear relationship between shrub AGB and shrub area. This methodology produces straightforward results that are easy to apply and interpret compared to more complex procedures that require identification of individual plants.

By applying the parameter estimates derived from our best models across the entire $\sim 10,800$ square metre region covered by shrubs within our study site, we calculated approximately $17,600 \mathrm{~kg}$ of total shrub aboveground biomass, corresponding to an average of $1.64 \mathrm{kgs} / \mathrm{m}^{2}$ in the area covered by shrubs. This is comparable to the results of Cunliffe et al. [9] who used shrub volume calculated from a UAS-derived CHM to estimate AGB of creosotebush and juniper shrubs in a dryland ecosystem, finding an average AGB of $1.45 \mathrm{~kg} / \mathrm{m}^{3}$ and $2.55 \mathrm{~kg} / \mathrm{m}^{3}$ for each species respectively. Across the entire study area the average of $0.66 \mathrm{~kg} / \mathrm{m}^{2}$ was similar to the $0.65 \mathrm{kgs} / \mathrm{m}^{2}$ reported in shrubland environments in the adjacent foothills region of the central east slopes of the Rocky Mountains [83]. 
When estimating the carrying capacity of bison within the reintroduction zone in Banff National Park, Steenweg et al. [54] calculated a total winter shrub intake rate of bison to be $\sim 97 \mathrm{~kg}$ over 181 days of winter. With 35 bison reported in the Banff herd as of winter 2019, if all animals stayed within our study site for the winter, they would consume approximately $3492 \mathrm{kgs}$ of shrub AGB, just over one tenth of what is available within the site. Our study area represents a very small fraction of the total bison reintroduction zone, so there is far more than the minimum shrub forage requirements calculated for the herd. Since other ungulates such as elk are also likely to browse on shrubs within the bison reintroduction zone [84], estimates of shrub AGB within Banff National Park are useful for understanding the availability of potential ungulate forage at a given point in time.

\subsection{Browsing Detection}

To determine if the high resolution of UAS imagery allowed changes in shrub AGB due to browsing to be detected using multi-temporal data, we conducted one UAS flight at the calibration site immediately after we manually "browsed" the 60 sample shrubs by using clippers to remove the leaves and twig ends in a manner similar to a browsing ungulate. We created a CHM, using the browsed shrub DSM, and calculated RGB VIs from the browsed model in the same way as with the non-browsed model, then identified and manually outlined an additional 60 shrubs that were clearly visible in the imagery and were not browsed. We then compared the change in CHM and RGB VI values between the browsed and un-browsed shrubs from before and after browsing to determine if a change could be detected.

Without radiometric correction, changes in reflectance values of RGB VIs across all shrubs due to very different illumination conditions for each survey flight were stronger than any signal that the browsing may have given and so were unable to detect changes in RGB VIs due to browsing. It would be valuable to determine if radiometric normalization of the imagery taken on different dates would make multi-temporal data more comparable and allow detection of changes in spectral values on the browsed shrubs caused by decreases in biomass due to removal of leaves and twigs via browsing.

Conversely, we were able to detect a change in shrub volume from the CHM in the browsed versus un-browsed shrubs. Un-browsed shrubs showed a mean change in volume of around $11 \%$ between the two data collection dates, which is within the range we would expect volume to change due to shrub movement in the wind and slight variations in illumination between image collection dates. Browsed shrubs decreased in volume by an average of $75 \%$, much more than would be expected due to shrub movement, indicating that changes in shrub AGB due to browsing by wildlife could be detected in UAS imagery. This approach may be useful for wildlife research and management where there is an interest in understanding fine-scale forage consumption and changes in forage availability over time.

\subsection{Allometric Equations}

We used a general shrub allometric equation developed previously in our study area [57] to calculate ground-based shrub AGB, making the assumption that relationships between shrub basal stem diameter and biomass had remained constant over the 12 years between the development and our application of the allometric equation. The application of generalized rather than species-specific allometric equations is not uncommon, especially for site-wide biomass estimates or in mixed-species environments when developing individual equations would be impractical [85]. For example, previous research in Alberta found no significant difference in the performance of species-specific and general shrub allometric equations for three shrub species in a boreal peatland [86].

In our study area, Betula and Salix shrubs have similar ranges of shapes and sizes, making a general shrub equation suitable for AGB estimation. However, when shrub species show greater variation in stem size and biomass, species- or genus-specific equations developed for that site are likely to have a stronger performance than general equations [87]. Additionally, applying general allometric equations to a new region, a species not included in the development of the equation, or to shrubs that fall outside of the domain of sizes over which that equation was developed can have 
lower accuracy and requires validation $[86,88]$. If possible, we recommend that researchers conduct destructive sampling of shrubs at their study site to validate existing allometric equations or derive new ones if there is an interest in highly-accurate biomass measurements, especially at the scale of individual shrubs $[85,88]$.

\subsection{Limitations and Recommendations}

Despite their good performance in this study, there are constraints to UAS-derived RGB VIs that researchers should consider when using them to estimate vegetation AGB. Automatic or pre-set exposure settings on many RGB cameras are based on overall light intensity, which can vary between images due to changes in solar elevation and clouds $[77,89,90]$, and small changes in radiation may lead to large differences in image tone unrelated to actual properties of the vegetation [36]. Extrapolating results from RGB data that has not been radiometrically corrected should be done with caution. Researchers should plan data collection and analysis to include radiometric correction methods, such as an empirical line calibration, which was originally developed for satellite imagery but can also be used for radiometric normalization of RGB and multispectral imagery [34,91,92].

In this study we could apply non-radiometrically corrected RGB VI-based models to predict shrub AGB at the validation site and still achieve strong model performance $\left(\mathrm{R}^{2}>0.75\right)$. However, the RMSE and MAE of the RGB models were much higher than that of the multispectral or CHM volume models when applied to the validation site, reaching up to $100 \%$ of observed AGB values. Similarly, the MBE indicated much greater overestimation of shrub AGB from the multivariate or RGB VI models compared to CHM volume or NDRE models or the two models that combined ratio-based RGB VIs with a NIR metric. This overestimation in the RGB models likely occurred because while the multispectral sensor comes with a radiometric target to calibrate reflectance values in the imagery and the CHM volume is less influenced by radiometric differences between sites, the RGB data were radiometrically uncorrected and so had a wider margin of error when models developed at one site were applied to another. However, the strong linear relationship between predicted and observed biomass values was still present in RGB VI models at the validation site. We expect that if data collection and analysis was planned to include radiometric correction of RGB imagery, the ability of models derived from these data to predict shrub biomass would be stronger with less error and bias in biomass estimates, allowing researchers to develop biomass prediction models at one site and apply them with confidence to other sites without the need for conducting multiple surveys with different sensors.

Although the volume structural metric did not relate as strongly to measured shrub biomass as spectral metrics, the single-variable regression model containing volume had a stable performance when applied at the validation site, with very similar $\mathrm{R}^{2}$ values between the two sites and relatively low RMSE, MAE, and MBE in validation, indicating less variation and bias in predicted biomass values when applied to a new spatial location compared to the non-radiometrically corrected VI-based models. The CHM was also useful for distinguishing shrub and non-shrub areas of the site during image classification, and changes in shrub AGB due to browsing were more detectable in the CHM volume than using spectral information. It is possible that difficulties interpolating the terrain beneath the shrub canopy when creating a DTM influenced the performance of our CHM as dense vegetation is known to make interpolation of an accurate terrain model from UAS imagery challenging $[2,41,43,48]$. Although the accumulated VI metrics were able to accurately estimate shrub AGB, it may be worth further exploring whether DTM creation and CHM-derived volume measurements can be improved for prediction of shrub AGB.

Single-variable linear regressions had equal or higher accuracy to multiple regression models combining several predictor variables. As an alternative to linear regression models, we could have combined all our spectral and structural predictors into machine learning regression algorithms. Machine learning regressions are being increasingly used with remotely-sensed data due to their ability to handle a high number of inter-correlated predictor variables that may have a non-linear relationship 
with the dependent variable $[34,38,73,76]$. Some researchers comparing machine learning random forest $(\mathrm{RF})$ models with alternate model forms for vegetation biomass estimation from UAS data found that RF models equaled or outperformed parametric regressions [34,66,73].

However, non-parametric regression methods are more complex to implement and interpret as they do not express relationships between the predictor and dependent variables in a single equation, losing some of the biological and physical meaning of a simple regression. Other researchers found that UAS data could predict vegetation AGB with equal or higher accuracy from simple regressions compared to machine learning methods $[5,61,73]$. For the purposes of broad-scale vegetation monitoring, linear regression models represent a straightforward and biologically-understandable approach to AGB modelling, and given the strong performance of the simple regressions relating RGB VI sum metrics to biomass found in this study, we believe that a potential increase in model accuracy from a machine-learning regression is not worth the increased computational effort and more opaque model application of this approach.

Finally, we note the reliance on allometric equations to derive our AGB reference data, a concession required by the remote helicopter-access location of our field sites. We advise future researchers to validate our findings with direct AGB measurements.

\section{Conclusions}

Our study is the second project in the peer-reviewed literature that we are aware of examining the use of UAS data to estimate the fine-scale biomass of shrubs. We found that a simple linear model can accurately predict the aboveground biomass of Betula and Salix shrubs from accumulated ratio-based RGB VI values across the vegetated area (calibration $R^{2}>0.88$; validation $R^{2}=0.76$ ), which is a novel methodology that fuses spectral and spatial information into one parsimonious metric. This method requires only a single UAS survey to collect RGB data that are useful for both classifying the shrub-covered region of the site and deriving biomass estimates, with the caveat that a process for radiometric correction should be included during the survey to ensure models are robust and transferable in space and time. No additional data collection is necessary and there is no need for creating digital terrain models using this method, since structural information on the shrub is captured along with spectral data using the accumulated RGB VI metric, although a canopy height model was useful for classifying shrub and grass regions of the study area. If data are radiometrically comparable, changes in shrub AGB over time may be quantified by repeatedly surveying the area of interest and looking at differences in accumulated VI values between surveys. The simplicity and accuracy of this workflow is ideal for mapping and monitoring shrub-dominated vegetation communities in remote areas, such as the backcountry montane meadows of Banff National Park that the newly reintroduced bison herd now occupies.

Author Contributions: Conceptualization, D.N.L. and G.J.M.; formal analysis, L.G.P.; funding acquisition, G.J.M.; investigation, L.G.P. and D.N.L.; methodology, D.N.L., L.G.P., and G.J.M.; resources, G.J.M.; supervision, G.J.M.; validation, L.G.P.; visualization, L.G.P.; writing—original draft, L.G.P.; writing一review and editing, L.G.P., D.N.L., and G.J.M. All authors have read and agreed to the published version of the manuscript.

Funding: This research was supported by The University of Calgary and the Natural Sciences and Engineering Council of Canada, grant number RGPIN-2016-06502.

Acknowledgments: We thank the Parks Canada Agency and its staff for assisting with planning and executing data collection, especially David Garrow and Brian Yakiwchuk for their assistance in the field and bison reintroduction project manager Karsten Heuer for providing project logistics. We acknowledge that our field work was conducted on the traditional territories of the people of the Treaty 7 region of southern Alberta.

Conflicts of Interest: The authors declare no conflicts of interest. 
Appendix A Summary of Correlations and Single-Variable Regressions between UAS-Derived Variables and Ground-Measured Shrub Biomass

Table A1. Pearson correlation statistic values ( $r$ ) and single-variable linear regression coefficients of determination $\left(\mathrm{R}^{2}\right)$ for each metric included in this study for estimating shrub aboveground biomass. Metrics were derived at the individual shrub level and related to allometric biomass.

\begin{tabular}{|c|c|c|c|c|c|c|c|c|c|c|c|c|}
\hline \multirow{2}{*}{ Variable } & \multicolumn{2}{|c|}{ Sum } & \multicolumn{2}{|c|}{ Mean } & \multicolumn{2}{|c|}{ Range } & \multicolumn{2}{|c|}{ Min } & \multicolumn{2}{|c|}{ Max } & \multicolumn{2}{|c|}{ STD } \\
\hline & $\mathbf{r}$ & $\mathbf{R}^{2}$ & $\mathbf{r}$ & $\mathbf{R}^{2}$ & $\mathbf{r}$ & $\mathbf{R}^{2}$ & $\mathbf{r}$ & $\mathbf{R}^{2}$ & $\mathbf{r}$ & $\mathbf{R}^{2}$ & $\mathbf{r}$ & $\mathbf{R}^{2}$ \\
\hline CHM.VOL & 0.87 & 0.75 & - & - & - & - & - & - & - & - & - & - \\
\hline MAX_H & - & - & - & - & - & - & - & - & 0.53 & 0.26 & - & - \\
\hline MEAN_H & - & - & 0.51 & 0.23 & - & - & - & - & - & - & - & - \\
\hline MSRED & 0.94 & 0.85 & -0.25 & -0.01 & 0.44 & 0.37 & -0.41 & 0.26 & 0.28 & 0.10 & -0.02 & 0.06 \\
\hline MSGREEN & 0.93 & 0.86 & -0.20 & 0.01 & 0.59 & 0.34 & -0.55 & 0.29 & 0.28 & 0.06 & 0.12 & 0.00 \\
\hline MSRE & 0.92 & 0.82 & -0.08 & -0.02 & 0.61 & 0.22 & -0.53 & 0.13 & 0.34 & 0.05 & 0.28 & -0.01 \\
\hline NIR & 0.92 & 0.85 & -0.02 & -0.02 & 0.61 & 0.37 & -0.50 & 0.23 & 0.34 & 0.10 & 0.30 & 0.08 \\
\hline NDVI & 0.94 & 0.88 & 0.26 & 0.04 & 0.32 & 0.08 & -0.13 & 0.00 & 0.31 & 0.08 & 0.02 & -0.02 \\
\hline NDRE & 0.94 & 0.88 & 0.10 & -0.01 & 0.44 & 0.18 & -0.15 & 0.01 & 0.32 & 0.09 & 0.04 & -0.02 \\
\hline BGRI & 0.92 & 0.85 & -0.12 & -0.01 & 0.66 & 0.43 & -0.59 & 0.34 & 0.18 & 0.02 & 0.33 & 0.09 \\
\hline BLUE & 0.91 & 0.83 & -0.20 & 0.01 & 0.46 & 0.23 & -0.59 & 0.34 & 0.15 & 0.01 & 0.43 & 0.17 \\
\hline BRATIO & 0.93 & 0.86 & -0.06 & -0.02 & 0.66 & 0.42 & -0.60 & 0.35 & 0.19 & 0.02 & 0.32 & 0.08 \\
\hline BRRI & 0.92 & 0.85 & 0.03 & -0.02 & 0.64 & 0.38 & -0.58 & 0.32 & 0.24 & 0.04 & 0.29 & 0.07 \\
\hline CIVE & -0.91 & 0.82 & -0.09 & -0.01 & 0.30 & 0.08 & -0.32 & 0.08 & 0.11 & 0.00 & 0.08 & -0.01 \\
\hline ExB & -0.89 & 0.79 & -0.13 & -0.01 & 0.72 & 0.51 & -0.67 & 0.44 & 0.18 & 0.02 & 0.37 & 0.12 \\
\hline ExG & 0.93 & 0.86 & 0.25 & 0.03 & 0.72 & 0.53 & -0.07 & -0.01 & 0.71 & 0.49 & 0.40 & 0.14 \\
\hline ExGR & 0.90 & 0.80 & 0.27 & 0.04 & 0.72 & 0.53 & -0.06 & -0.01 & 0.72 & 0.51 & 0.39 & 0.14 \\
\hline ExR & -0.40 & 0.14 & -0.30 & 0.06 & 0.72 & 0.53 & -0.74 & 0.53 & 0.05 & -0.02 & 0.38 & 0.13 \\
\hline GBRI & 0.93 & 0.87 & 0.13 & -0.01 & 0.48 & 0.22 & -0.67 & 0.45 & 0.48 & 0.22 & 0.34 & 0.10 \\
\hline GRATIO & 0.94 & 0.89 & 0.23 & 0.03 & 0.74 & 0.55 & -0.09 & -0.01 & 0.72 & 0.50 & 0.42 & 0.17 \\
\hline GREEN & 0.93 & 0.87 & -0.31 & 0.05 & 0.64 & 0.43 & -0.72 & 0.51 & 0.31 & 0.08 & 0.59 & 0.33 \\
\hline GRRI & 0.94 & 0.88 & 0.35 & 0.09 & 0.74 & 0.54 & -0.05 & -0.02 & 0.73 & 0.52 & 0.39 & 0.13 \\
\hline IKAW & 0.93 & 0.86 & -0.02 & -0.02 & 0.65 & 0.39 & -0.24 & 0.04 & 0.61 & 0.36 & 0.26 & 0.06 \\
\hline INT & 0.93 & 0.86 & -0.33 & 0.07 & 0.57 & 0.34 & -0.72 & 0.50 & 0.17 & 0.01 & 0.53 & 0.27 \\
\hline MGRVI & 0.90 & 0.80 & 0.35 & 0.09 & 0.65 & 0.41 & -0.05 & -0.02 & 0.71 & 0.50 & 0.27 & 0.06 \\
\hline MVARI & 0.87 & 0.75 & 0.14 & -0.01 & 0.50 & 0.24 & -0.49 & 0.23 & 0.46 & 0.20 & 0.27 & 0.06 \\
\hline NGBI & 0.93 & 0.87 & 0.12 & -0.01 & 0.68 & 0.44 & -0.18 & 0.02 & 0.62 & 0.37 & 0.33 & 0.10 \\
\hline NGRDI & 0.90 & 0.80 & 0.35 & 0.09 & 0.68 & 0.45 & -0.05 & -0.02 & 0.72 & 0.51 & 0.29 & 0.07 \\
\hline RBRI & 0.94 & 0.88 & 0.00 & -0.02 & 0.48 & 0.23 & -0.71 & 0.50 & 0.48 & 0.22 & 0.30 & 0.07 \\
\hline RED & 0.93 & 0.87 & -0.42 & 0.13 & 0.55 & 0.31 & -0.74 & 0.54 & 0.10 & -0.01 & 0.48 & 0.22 \\
\hline RGBVI & 0.93 & 0.87 & 0.20 & 0.01 & 0.66 & 0.43 & -0.12 & 0.00 & 0.62 & 0.37 & 0.35 & 0.10 \\
\hline RGRI & 0.94 & 0.88 & -0.35 & 0.09 & 0.55 & 0.29 & -0.71 & 0.49 & 0.06 & -0.01 & 0.18 & 0.02 \\
\hline RRATIO & 0.94 & 0.89 & -0.31 & 0.08 & 0.42 & 0.13 & -0.42 & 0.16 & 0.14 & 0.00 & -0.02 & -0.02 \\
\hline TGI & 0.93 & 0.86 & 0.06 & -0.01 & 0.32 & 0.09 & -0.15 & 0.01 & 0.25 & 0.05 & 0.04 & -0.02 \\
\hline VARI & 0.89 & 0.80 & 0.36 & 0.10 & 0.56 & 0.29 & -0.04 & -0.02 & 0.64 & 0.40 & 0.19 & 0.02 \\
\hline VDVI & 0.93 & 0.86 & 0.23 & 0.03 & 0.73 & 0.54 & -0.09 & -0.01 & 0.71 & 0.49 & 0.41 & 0.15 \\
\hline WI & -0.90 & 0.81 & 0.33 & 0.09 & 0.09 & -0.01 & -0.07 & -0.01 & 0.09 & -0.01 & -0.22 & 0.03 \\
\hline
\end{tabular}

\section{Appendix B Classification Details and Accuracy Assessment Results}

We conducted an object-based image classification to identify and classify the region of the study area covered by shrubs, grass, and neither in order to apply each vegetation biomass estimation model. To classify the imagery, we used the rule-based feature extraction tool in the software ENVI. The classification workflow has two main steps: first, the image is segmented into objects of a set size, and the user must determine values ranging between 0 and 100 for the scale parameter, which controls the initial size of the objects, and the merge parameter, which controls the degree to which smaller objects are merged with their neighbours. Then, a set of rules are defined for each class, which can include spatial or spectral properties of objects and are weighted by importance, and objects are assigned to the class with rules they fit within. 
We used three raster images as input data for the classification that were most useful for separating the three classes: a canopy height model, the blue-green radio index (BGRI), and the red ratio vegetation index. The scale and merge parameters were set to 40 , which resulted in objects most closely aligning to real objects within the imagery, then rules for three classes were defined: shrubs, grass, and neither, which included dead trees, small rocks, and gravel. Using trial and error, we determined the best ranges of values from each of the three input data layers to separate the shrub, grass, and other classes most accurately.

The shrub class was defined using CHM values greater than 0.4 with a rule weight of 1 , BGRI values less than 0.66 with a rule weight of 0.75 , and red ratio values between 100 and 140 with a rule weight of 0.5. The grass class was defined using CHM values less than 0.4 with a rule weight of 1 , BGRI values greater than 0.6 with a rule weight of 0.75 , and red ratio values between 140 and 255 with a rule weight of 0.5 . The neither class was defined using BGRI values greater than 0.95 with a rule weight of 5 . The result of the classification was a shapefile with the boundaries of each of the three classes, which was imported into ArcGIS.

To assess the accuracy of the classification, we generated 200 points distributed randomly across the image and visually determined the true class and rule-based class each point fell within. We then determined the accuracy of the classification using a confusion matrix by calculating errors of omission and commission and producer's and user's accuracy for each class.

The accuracy assessment of our classified image indicated the object-based classification did a very good job of distinguishing between grass, shrub, and other classes (Table A2). Out of the 200 random points generated, 193 were assigned to the correct class, giving a total accuracy of 0.965 . The shrub class had a producer's accuracy of 0.99 and a user's accuracy of 0.97 , with slightly more errors of commission than omission. The grass class had a producer's accuracy of 0.96 and a user's accuracy of 0.95 , with slightly higher errors of omission compared to commission. The neither class made up a very small part of the overall scene and had a producer's accuracy of 0.73 and a user's accuracy of 1.0, indicating no errors of commission.

Table A2. Confusion matrix resulting from the classification accuracy assessment of the calibration site.

\begin{tabular}{cccccc}
\hline & \multicolumn{5}{c}{ Predicted Class } \\
\cline { 2 - 6 } & & Shrub & Grass & Neither & Total \\
\multirow{3}{*}{ Observed Class } & Shrub & 111 & 1 & 0 & 112 \\
& Grass & 3 & 74 & 0 & 77 \\
& Neither & 0 & 3 & 8 & 11 \\
\cline { 2 - 6 } & Total & 114 & 78 & 8 & 200 \\
\hline
\end{tabular}

Classification of grass as shrubs or vice versa tended to occur in small gaps in densely vegetated areas or around the edges of shrub patches where it was more challenging to distinguish between sparse shrub leaves and grass. Classification of a large gravel path in the northeast corner of the study site and of large dead trees was very accurate, but the edges of smaller tree stumps or dead branches were occasionally misclassified as grass. Overall classification of shrubs, grass, and neither had high accuracy and upon visual inspection lined up very well with the true locations of each class. 


\section{Appendix C Scatterplots of Relationships between Observed and Predicted shrub AGB Values}

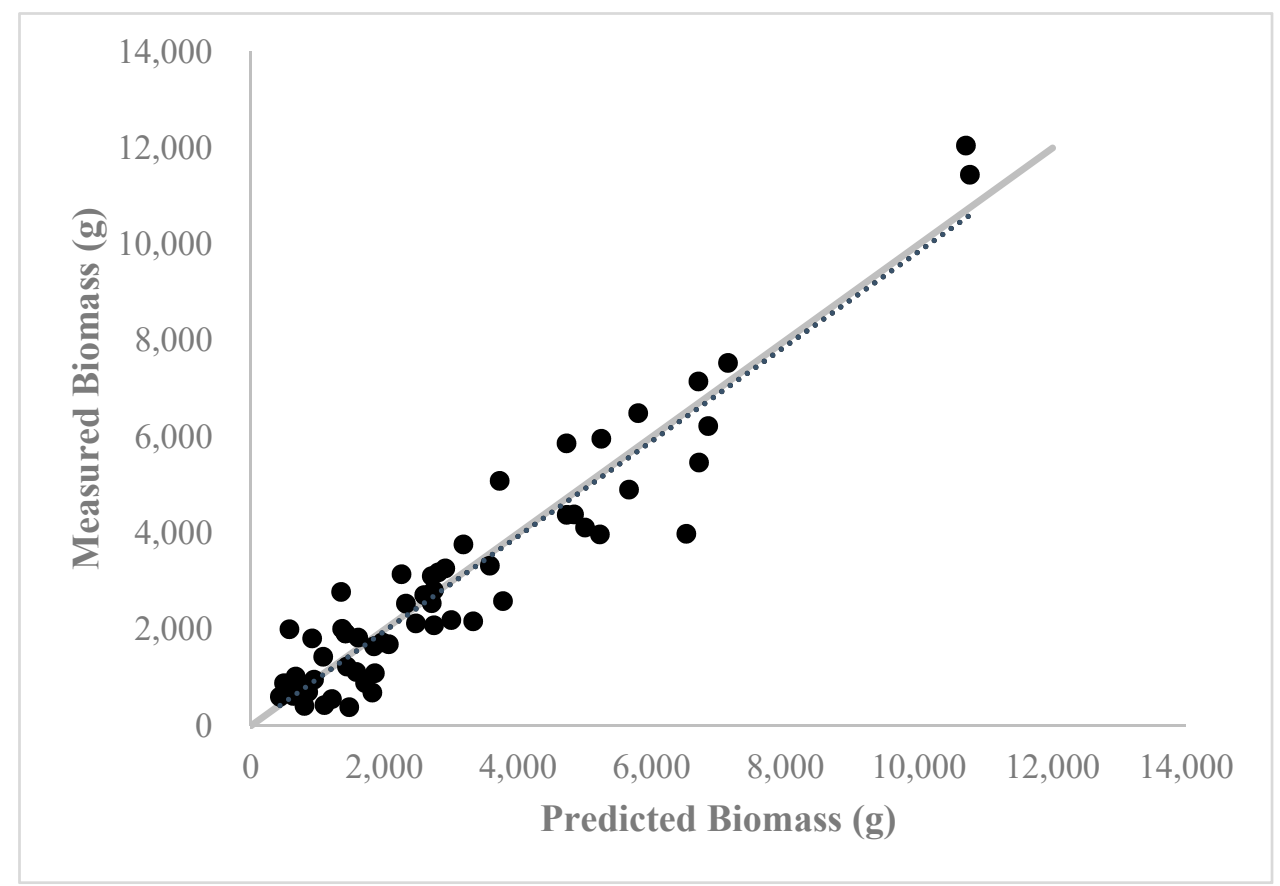

(a)

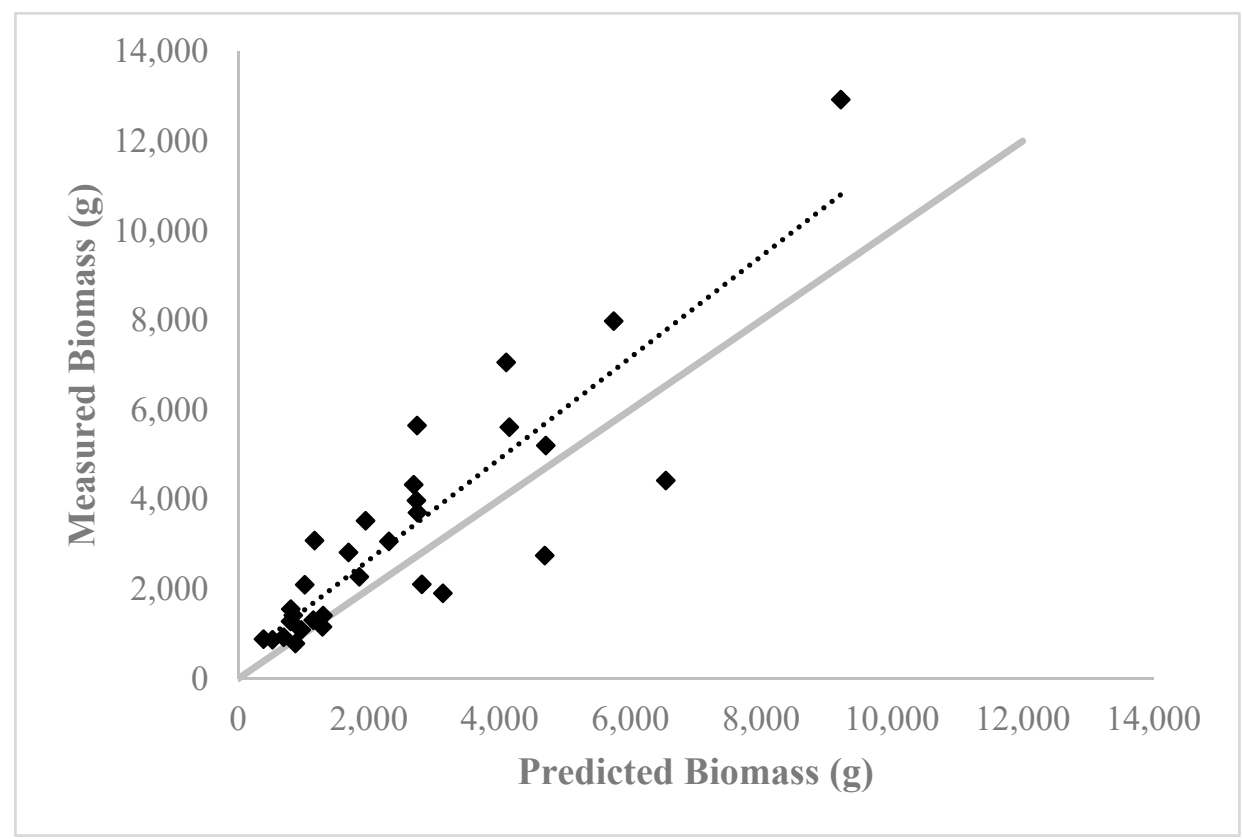

(b)

Figure A1. Relationship between predicted and ground measured shrub biomass from the aboveground biomass estimation model containing the red ratio accumulated vegetation index and standard deviation of the multispectral red band values at the (a) calibration site (60 shrubs total) and (b) validation site (30 shrubs total). 1:1 line of agreement is shown in light grey. 


\section{References}

1. Arnon, A.I.; Ungar, E.D.; Svoray, T.; Shachak, M.; Blankman, J.; Perevolotsky, A. The application of remote sensing to study shrub-herbaceous relations at a high spatial resolution. Isr. J. Plant Sci. 2007, 55, 73-82. [CrossRef]

2. Zhang, H.; Sun, Y.; Chang, L.; Qin, Y.; Chen, J.; Qin, Y.; Du, J.; Yi, S.; Wan, Y. Estimation of Grassland Canopy Height and Aboveground Biomass at the Quadrat Scale Using Unmanned Aerial Vehicle. Remote Sens. 2018, 10, 1-19. [CrossRef]

3. Scurlock, J.M.O.; Hall, D.O. The global carbon sink: A grassland perspective. Glob. Chang. Biol. 1998, 4, 229-233. [CrossRef]

4. Van Oijen, M.; Bellocchi, G.; Höglind, M. Effects of climate change on grassland biodiversity and productivity: The need for a diversity of models. Agronomy 2018, 8, 14. [CrossRef]

5. Borra-Serrano, I.; De Swaef, T.; Muylle, H.; Nuyttens, D.; Vangeyte, J.; Mertens, K.; Saeys, W.; Somers, B.; Roldán-Ruiz, I.; Lootens, P. Canopy height measurements and non-destructive biomass estimation of Lolium perenne swards using UAV imagery. Grass Forage Sci. 2019, 74, 356-369. [CrossRef]

6. Zandler, H.; Brenning, A.; Samimi, C. Quantifying dwarf shrub biomass in an arid environment: Comparing empirical methods in a high dimensional setting. Remote Sens. Environ. 2015, 158, 140-155. [CrossRef]

7. Wang, Z.; Bastin, G.N.; Liu, L.; Caccetta, P.A.; Peng, D. Estimating woody above-ground biomass in an arid zone of central Australia using Landsat imagery. J. Appl. Remote Sens. 2015, 9, 096036. [CrossRef]

8. Adhikari, A.; White, J.D. Climate change impacts on regenerating shrubland productivity. Ecol. Modell. 2016, 337, 211-220. [CrossRef]

9. Cunliffe, A.M.; Brazier, R.E.; Anderson, K. Ultra-fine grain landscape-scale quantification of dryland vegetation structure with drone-acquired structure-from-motion photogrammetry. Remote Sens. Environ. 2016, 183, 129-143. [CrossRef]

10. Anderson, K.E.; Glenn, N.F.; Spaete, L.P.; Shinneman, D.J.; Pilliod, D.S.; Arkle, R.S.; McIlroy, S.K.; Derryberry, D.W.R. Estimating vegetation biomass and cover across large plots in shrub and grass dominated drylands using terrestrial lidar and machine learning. Ecol. Indic. 2018, 84, 793-802. [CrossRef]

11. Chen, W.; Zhao, J.; Cao, C.; Tian, H. Shrub biomass estimation in semi-arid sandland ecosystem based on remote sensing technology. Glob. Ecol. Conserv. 2018, 16, e00479. [CrossRef]

12. Adhikari, A.; White, J.D. Plant water use characteristics of five dominant shrub species of the Lower Rio Grande Valley, Texas, USA: Implications for shrubland restoration and conservation. Conserv. Physiol. 2014, 2,1-9. [CrossRef]

13. Houghton, R.A. Balancing the Global Carbon Budget. Annu. Rev. Earth Planet. Sci. 2007, 35, $313-347$. [CrossRef]

14. Bradley, B.A.; Houghton, R.A.; Mustard, J.F.; Hamburg, S.P. Invasive grass reduces aboveground carbon stocks in shrublands of the Western US. Glob. Chang. Biol. 2006, 12, 1815-1822. [CrossRef]

15. Greaves, H.E.; Vierling, L.A.; Eitel, J.U.H.; Boelman, N.T.; Magney, T.S.; Prager, C.M.; Griffin, K.L. High-resolution mapping of aboveground shrub biomass in Arctic tundra using airborne lidar and imagery. Remote Sens. Environ. 2016, 184, 361-373. [CrossRef]

16. Li, A.; Glenn, N.F.; Olsoy, P.J.; Mitchell, J.J.; Shrestha, R. Aboveground biomass estimates of sagebrush using terrestrial and airborne LiDAR data in a dryland ecosystem. Agric. For. Meteorol. 2015, 213, $138-147$. [CrossRef]

17. Van Auken, O.W. Shrub Invasions of North American Semiarid Grasslands. Annu. Rev. Ecol. Syst. 2000, 31, 197-215. [CrossRef]

18. Holmes, P.M. Shrubland restoration following woody alien invasion and mining: Effects of topsoil depth, seed source, and fertilizer addition. Restor. Ecol. 2001, 9, 71-84. [CrossRef]

19. Fraser, R.H.; Olthof, I.; Lantz, T.C.; Schmitt, C. UAV photogrammetry for mapping vegetation in the low-Arctic. Arct. Sci. 2016, 2, 79-102. [CrossRef]

20. Brantley, S.T.; Zinnert, J.C.; Young, D.R. Application of hyperspectral vegetation indices to detect variations in high leaf area index temperate shrub thicket canopies. Remote Sens. Environ. 2011, 115, 514-523. [CrossRef]

21. Estornell, J.; Ruiz, L.A.; Velázquez-Martí, B.; Hermosilla, T. Estimation of biomass and volume of shrub vegetation using LiDAR and spectral data in a Mediterranean environment. Biomass Bioenergy 2012, 46, 710-721. [CrossRef] 
22. Estornell, J.; Ruiz, L.A.; Velázquez-Martí, B.; Fernández-Sarría, A. Estimation of shrub biomass by airborne LiDAR data in small forest stands. For. Ecol. Manag. 2011, 262, 1697-1703. [CrossRef]

23. Adhikari, A.; Yao, J.; Sternberg, M.; McDowell, K.; White, J.D. Aboveground biomass of naturally regenerated and replanted semi-tropical shrublands derived from aerial imagery. Landsc. Ecol. Eng. 2017, 13, 145-156. [CrossRef]

24. Willkomm, M.; Bolten, A.; Bareth, G. Non-destructive monitoring of rice by hyperspectral in-field spectrometry and UAV-based remote sensing: Case study of field-grown rice in North Rhine-Westphalia, Germany. Int. Arch. Photogramm. Remote Sens. Spat. Inf. Sci.-ISPRS Arch. 2016, XLI-B1, 1071-1077. [CrossRef]

25. Anderson, K.; Gaston, K.J. Lightweight unmanned aerial vehicles will revolutionize spatial ecology. Front. Ecol. Environ. 2013, 11, 138-146. [CrossRef]

26. Schirrmann, M.; Giebel, A.; Gleiniger, F.; Pflanz, M.; Lentschke, J.; Dammer, K. Monitoring Agronomic Parameters of Winter Wheat Crops with Low-Cost UAV Imagery. Remote Sens. 2016, 8, 706. [CrossRef]

27. Jayathunga, S.; Owari, T.; Tsuyuki, S. Digital Aerial Photogrammetry for Uneven-Aged Forest Management: Assessing the Potential to Reconstruct Canopy Structure and Estimate Living Biomass. Remote Sens. 2019, 11,338. [CrossRef]

28. Kachamba, D.J.; Ørka, H.O.; Gobakken, T.; Eid, T.; Mwase, W. Biomass Estimation Using 3D Data from Unmanned Aerial Vehicle Imagery in a Tropical Woodland. Remote Sens. 2016, 8, 968. [CrossRef]

29. Olsoy, P.J.; Forbey, J.S.; Shipley, L.A.; Rachlow, J.L.; Robb, B.C.; Nobler, J.D.; Thornton, D.H. Mapping foodscapes and sagebrush morphotypes with unmanned aerial systems for multiple herbivores. Landsc. Ecol. 2020, 35, 921-936. [CrossRef]

30. Michez, A.; Bauwens, S.; Brostaux, Y.; Hiel, M.P.; Garré, S.; Lejeune, P.; Dumont, B. How far can consumer-grade UAV RGB imagery describe crop production? A 3D and multitemporal modeling approach applied to Zea mays. Remote Sens. 2018, 10, 1798. [CrossRef]

31. Alonzo, M.; Andersen, H.; Morton, D.C.; Cook, B.D. Quantifying Boreal Forest Structure and Composition Using UAV Structure from Motion. Forests 2018, 9, 119. [CrossRef]

32. Cen, H.; Wan, L.; Zhu, J.; Li, Y.; Li, X.; Zhu, Y.; Weng, H.; Wu, W.; Yin, W.; Xu, C.; et al. Dynamic monitoring of biomass of rice under different nitrogen treatments using a lightweight UAV with dual image-frame snapshot cameras. Plant Methods 2019, 15, 1-16. [CrossRef]

33. Näsi, R.; Viljanen, N.; Kaivosoja, J.; Alhonoja, K.; Hakala, T.; Markelin, L.; Honkavaara, E. Estimating Biomass and Nitrogen Amount of Barley and Grass Using UAV and Aircraft Based Spectral and. Remote Sens. 2018, 10, 1082. [CrossRef]

34. Jiang, Q.; Fang, S.; Peng, Y.; Gong, Y.; Zhu, R.; Wu, X.; Ma, Y.; Duan, B.; Liu, J. UAV-Based Biomass Estimation for Rice-Combining Spectral, TIN-Based Structural and Meteorological Features. Remote Sens. 2019, 11, 890. [CrossRef]

35. Bendig, J.; Bolten, A.; Bennertz, S.; Broscheit, J.; Eichfuss, S.; Bareth, G. Estimating Biomass of Barley Using Crop Surface Models (CSMs) Derived from UAV-Based RGB Imaging. Remote Sens. 2014, 6, 10395-10412. [CrossRef]

36. Bendig, J.; Yu, K.; Aasen, H.; Bolten, A.; Bennertz, S.; Broscheit, J.; Gnyp, M.L.; Bareth, G. Combining UAV-based plant height from crop surface models, visible, and near infrared vegetation indices for biomass monitoring in barley. Int. J. Appl. Earth Obs. Geoinf. 2015, 39, 79-87. [CrossRef]

37. Yue, J.; Yang, G.; Li, C.; Li, Z.; Wang, Y.; Feng, H.; Xu, B. Estimation of winter wheat above-ground biomass using unmanned aerial vehicle-based snapshot hyperspectral sensor and crop height improved models. Remote Sens. 2017, 9, 708. [CrossRef]

38. Moeckel, T.; Dayananda, S.; Nidamanuri, R.R.; Nautiyal, S.; Hanumaiah, N.; Buerkert, A.; Wachendorf, M. Estimation of Vegetable Crop Parameter by Multi-temporal UAV-Borne Images. Remote Sens. 2018, 10, 805. [CrossRef]

39. Ballesteros, R.; Fernando, J.; David, O.; Moreno, M.A. Onion biomass monitoring using UAV-based RGB. Precis. Agric. 2018, 19, 840-857. [CrossRef]

40. Domingo, D.; Ørka, H.O.; Næsset, E.; Kachamba, D.; Gobakken, T. Effects of UAV Image Resolution, Camera Type, and Image Overlap on Accuracy of Biomass Predictions in a Tropical Woodland. Remote Sens. 2019, 11, 948. [CrossRef]

41. Zahawi, R.A.; Dandois, J.P.; Holl, K.D.; Nadwodny, D.; Reid, J.L.; Ellis, E.C. Using lightweight unmanned aerial vehicles to monitor tropical forest recovery. Biol. Conserv. 2015, 186, 287-295. [CrossRef] 
42. Ota, T.; Ogawa, M.; Mizoue, N.; Fukumoto, K.; Yoshida, S. Forest Structure Estimation from a UAV-Based Photogrammetric Point Cloud in Managed Temperate Coniferous Forests. Forests 2017, 8, 343. [CrossRef]

43. Guerra-Hernández, J.; González-Ferreiro, E.; Monleón, V.J.; Faias, S.; Tomé, M.; Díaz-Varela, R. Use of Multi-Temporal UAV-Derived Imagery for Estimating Individual Tree Growth in Pinus pinea Stands. Forests 2017, 8, 300. [CrossRef]

44. Jing, R.; Gong, Z.; Zhao, W.; Pu, R.; Deng, L. Above-bottom biomass retrieval of aquatic plants with regression models and SfM data acquired by a UAV platform - A case study in Wild Duck Lake Wetland, Beijing, China. ISPRS J. Photogramm. Remote Sens. 2017, 134, 122-134. [CrossRef]

45. Otero, V.; Van De Kerchove, R.; Satyanarayana, B.; Martínez-espinosa, C.; Amir, M.; Fisol, B.; Rodila, M.; Ibrahim, B.; Sulong, I.; Mohd-lokman, H.; et al. Managing mangrove forests from the sky: Forest inventory using field data and Unmanned Aerial Vehicle (UAV) imagery in the Matang Mangrove Forest Reserve, peninsular Malaysia. For. Ecol. Manag. 2018, 411,35-45. [CrossRef]

46. Doughty, C.L.; Cavanaugh, K.C. Mapping Coastal Wetland Biomass from High Resolution Unmanned Aerial Vehicle (UAV) Imagery. Remote Sens. 2019, 11, 540. [CrossRef]

47. Wang, C.; Price, K.P.; Van Der Merwe, D.; An, N.; Wang, H. Modeling Above-Ground Biomass in Tallgrass Prairie Using Ultra-High Spatial Resolution sUAS Imagery. Photogramm. Eng. Remote Sens. 2014, 80, 1151-1159. [CrossRef]

48. Wijesingha, J.; Moeckel, T.; Hensgen, F.; Wachendorf, M. Evaluation of 3D point cloud-based models for the prediction of grassland biomass. Int. J. Appl. Earth Obs. Geoinf. 2019, 78, 352-359. [CrossRef]

49. Hartnett, D.C.; Hickman, K.R.; Fischer Walter, L.E. Effects of bison grazing, fire, and topography on floristic diversity in tallgrass prairie. J. Range Manag. 1996, 49, 413-420. [CrossRef]

50. Fuhlendorf, S.D.; Engle, D.M. Application of the fire-grazing interaction to restore a shifting mosaic on tallgrass prairie. J. Appl. Ecol. 2004, 41, 604-614. [CrossRef]

51. Fulhendorf, S.; Engle, D.M. Restoring Heterogeneity on Rangelands: Ecosystem Management Based on Evolutionary Grazing Patterns. Bioscience 2001, 51, 625-632. [CrossRef]

52. Freese, C.H.; Aune, K.E.; Boyd, D.P.; Derr, J.N.; Forrest, S.C.; Cormack Gates, C.; Gogan, P.J.P.; Grassel, S.M.; Halbert, N.D.; Kunkel, K.; et al. Second chance for the plains bison. Biol. Conserv. 2007, 136, 175-184. [CrossRef]

53. COSEWIC. COSEWIC Assessment and Status Report on the Plains Bison (Bison Bison Bison) and Wood Bison (Bison Bison Athabascae) in Canada; COSEWIC: Ottawa, ON, Canada, 2013.

54. Steenweg, R.; Hebblewhite, M.; Gummer, D.; Low, B.; Hunt, B. Assessing potential habitat and carrying capacity for reintroduction of plains bison (Bison bison bison) in Banff National Park. PLoS ONE 2016, 11, e0150065. [CrossRef]

55. Knapp, A.K.; Blair, J.M.; Briggs, J.M.; Collins, S.L.; Hartnett, D.C.; Johnson, L.C.; Towne, E.G.; John, M.; Scott, L. North Keystone Role of Bison in American Tallgrass Prairie Bison increase habitat heterogeneity processes. Bioscience 1999, 49, 39-50. [CrossRef]

56. Holland, W.D.; Coen, G. Ecological (Biophysical) Land Classification of Banff and Jasper National Parks; Canadian Wildlife Service: Edmonton, AB, Canada, 1983.

57. Hebblewhite, M. Linking Predation Risk and Forage to Ungulate Population Dynamics; University of Alberta: Edmonton, AB, Canada, 2006.

58. Assmann, J.J.; Kerby, J.T.; Cunliffe, A.M.; Myers-Smith, I.H. Vegetation monitoring using multispectral sensors-Best practices and lessons learned from high latitudes. J. Unmanned Veh. Syst. 2019, 7, 54-75. [CrossRef]

59. Lowe, D.G. Distinctive image features from scale-invariant keypoints. Int. J. Comput. Vis. 2004, 60, 91-110. [CrossRef]

60. Whitehead, K.; Hugenholtz, C.H. Remote sensing of the environment with small unmanned aircraft systems (UASs), part 1: A review of progress and challenges. J. Unmanned Veh. Syst. 2014, 2, 69-85. [CrossRef]

61. Maimaitijiang, M.; Sagan, V.; Sidike, P.; Maimaitiyiming, M.; Hartling, S.; Peterson, K.T.; Maw, M.J.W.; Shakoor, N.; Mockler, T.; Fritschi, F.B. Vegetation Index Weighted Canopy Volume Model (CVM VI) for soybean biomass estimation from Unmanned Aerial System-based RGB imagery. ISPRS J. Photogramm. Remote Sens. 2019, 151, 27-41. [CrossRef]

62. Lin, J.; Wang, M.; Ma, M.; Lin, Y. Aboveground Tree Biomass Estimation of Sparse Subalpine Coniferous Forest with UAV Oblique Photography. Remote Sens. 2018, 10, 1849. [CrossRef] 
63. Peña, J.M.; De Castro, A.I.; Torres-sánchez, J.; Andújar, D.; San Martin, C.; Dorado, J.; Fernández-Quintanilla, C.; López-Granados, F. Estimating tree height and biomass of a poplar plantation with image-based UAV technology. Agric. Food 2018, 3, 313-326. [CrossRef]

64. Rouse, J.W.; Hass, R.H.; Schell, J.A.; Deering, D.W. Monitoring vegetation systems in the great plains with ERTS. Third Earth Resour. Technol. Satell. Symp. 1973, 1, 309-317.

65. Barnes, E.; Clarke, T.R.; Richards, S.E.; Colaizzi, P.D.; Haberland, J.; Kostrzewski, M.; Waller, P.; Choi, C.; Riley, E.; Thompson, T.; et al. Coincedent detection of crop water stress, nitrogen status, and canopy density using ground-based multispectral data. In Proceedings of the Fifth International Conference on Precision Agriculture, Bloomington, MN, USA, 16-19 July 2000; pp. 1-15.

66. Yue, J.; Feng, H.; Jin, X.; Yuan, H.; Li, Z.; Zhou, C.; Yang, G.; Tian, Q. A Comparison of Crop Parameters Estimation Using Images from UAV-Mounted Snapshot Hyperspectral Sensor and High-Definition Digital Camera. Remote Sens. 2018, 10, 1138. [CrossRef]

67. Kataoka, T.; Okamoto, H. Crop Growth Estimation System Using Machine Vision. In Proceedings of the 2003 IEEE/ASME International Conference on Advanced Intelligent Mechatronics (AIM 2003), Kobe, Japan, 20-24 July 2003; pp. 1079-1083.

68. Kawashima, S.; Nakatani, M. An algorithm for estimating chlorophyll content in leaves using a video camera. Ann. Bot. 1998, 81, 49-54. [CrossRef]

69. Hunt, E.R.; Daughtry, C.S.T.; Mirsky, S.B.; Hively, W.D. Remote sensing with simulated unmanned aircraft imagery for precision agriculture applications. IEEE J. Sel. Top. Appl. Earth Obs. Remote Sens. 2014, 7, 4566-4571. [CrossRef]

70. Gitelson, A.A.; Viña, A.; Arkebauer, T.J.; Rundquist, D.C.; Keydan, G.; Leavitt, B. Remote estimation of leaf area index and green leaf biomass in maize canopies. Geophys. Res. Lett. 2003, 30. [CrossRef]

71. Thompson, C.G.; Kim, R.S.; Aloe, A.M.; Becker, B.J. Extracting the Variance In flation Factor and Other Multicollinearity Diagnostics from Typical Regression Results. Basic Appl. Soc. Psych. 2017, 39, 81-90. [CrossRef]

72. Burnham, K.P.; Anderson, D.R. Multimodel inference: Understanding AIC and BIC in model selection. Sociol. Methods Res. 2004, 33, 261-304. [CrossRef]

73. Lu, N.; Zhou, J.; Han, Z.; Li, D.; Cao, Q.; Yao, X.; Tian, Y.; Zhu, Y.; Cao, W.; Cheng, T. Improved estimation of aboveground biomass in wheat from RGB imagery and point cloud data acquired with a low-cost unmanned aerial vehicle system. Plant Methods 2019, 15, 1-16. [CrossRef]

74. Gitelson, A.A.; Kaufman, Y.J.; Merzlyak, M.N. Use of a green channel in remote sensing of global vegetation from EOS- MODIS. Remote Sens. Environ. 1996, 58, 289-298. [CrossRef]

75. Li, W.; Niu, Z.; Chen, H.; Li, D.; Wu, M.; Zhao, W. Remote estimation of canopy height and aboveground biomass of maize using high-resolution stereo images from a low-cost unmanned aerial vehicle system. Ecol. Indic. 2016, 67, 637-648. [CrossRef]

76. Han, L.; Yang, G.; Dai, H.; Xu, B.; Yang, H.; Feng, H.; Li, Z.; Yang, X. Modeling maize above-ground biomass based on machine learning approaches using UAV remote-sensing data. Plant Methods 2019, 15, 1-19. [CrossRef] [PubMed]

77. Roth, L.; Streit, B. Predicting cover crop biomass by lightweight UAS-based RGB and NIR photography: An applied photogrammetric approach. Precis. Agric. 2018, 19, 93-114. [CrossRef]

78. Li, A.; Dhakal, S.; Glenn, N.F.; Spaete, L.P.; Shinneman, D.J.; Pilliod, D.S.; Arkle, R.S.; McIlroy, S.K. Lidar aboveground vegetation biomass estimates in shrublands: Prediction, uncertainties and application to coarser scales. Remote Sens. 2017, 9, 903. [CrossRef]

79. Brubaker, K.M.; Johnson, Q.K.; Kaye, M.W. Spatial patterns of tree and shrub biomass in a deciduous forest using leaf-off and leaf-on lidar. Can. J. For. Res. 2018, 48, 1020-1033. [CrossRef]

80. Olsoy, P.J.; Glenn, N.F.; Clark, P.E. Estimating sagebrush biomass using terrestrial laser scanning. Rangel. Ecol. Manag. 2014, 67, 224-228. [CrossRef]

81. Olsoy, P.J.; Glenn, N.F.; Clark, P.E.; Derryberry, D.W.R. Aboveground total and green biomass of dryland shrub derived from terrestrial laser scanning. ISPRS J. Photogramm. Remote Sens. 2014, 88, 166-173. [CrossRef]

82. Niu, Y.; Zhang, L.; Zhang, H.; Han, W.; Peng, X. Estimating Above-Ground Biomass of Maize Using Features Derived from UAV-Based RGB Imagery. Remote Sens. 2019, 11, 1261. [CrossRef] 
83. Beyer, H.; Frair, J.; Visscher, D.R.; Fortin, D.; Merrill, E.H.; Boyce, M.S.; Allen, J. Vegetation Map and Dynamics of elk Forage for the Central East Slopes elk and Wolf Study; University of Alberta, Department of Biological Sciences: Edmonton, AB, Canada, 2004.

84. Sachro, L.L.; Strong, W.L.; Gates, C.C. Prescribed burning effects on summer elk forage availability in the subalpine zone, Banff National Park, Canada. J. Environ. Manag. 2005, 77, 183-193. [CrossRef]

85. Paul, K.I.; Roxburgh, S.H.; England, J.R.; Ritson, P.; Hobbs, T.; Brooksbank, K.; John Raison, R.; Larmour, J.S.; Murphy, S.; Norris, J.; et al. Development and testing of allometric equations for estimating above-ground biomass of mixed-species environmental plantings. For. Ecol. Manag. 2013, 310, 483-494. [CrossRef]

86. He, A.; McDermid, G.J.; Rahman, M.M.; Strack, M.; Saraswati, S.; Xu, B. Developing allometric equations for estimating shrub biomass in a boreal fen. Forests 2018, 9, 569. [CrossRef]

87. Buech, R.R.; Rugg, D.J. Biomass Relations of Shrub Components and their Generality. For. Ecol. Manag. 1989, 26, 257-264. [CrossRef]

88. Paul, K.I.; Radtke, P.J.; Roxburgh, S.H.; Larmour, J.; Waterworth, R.; Butler, D.; Brooksbank, K.; Ximenes, F. Validation of allometric biomass models: How to have confidence in the application of existing models. For. Ecol. Manag. 2018, 412, 70-79. [CrossRef]

89. Hunt, E.R.; Cavigelli, M.; Daughtry, C.S.T.; McMurtrey, J.E.; Walthall, C.L. Evaluation of digital photography from model aircraft for remote sensing of crop biomass and nitrogen status. Precis. Agric. 2005, 6, 359-378. [CrossRef]

90. Possoch, M.; Bieker, S.; Hoffmeister, D.; Bolten, A.A.; Schellberg, J.; Bareth, G. Multi-Temporal crop surface models combined with the rgb vegetation index from UAV-based images for forage monitoring in grassland. Int. Arch. Photogramm. Remote Sens. Spat. Inf. Sci.-ISPRS Arch. 2016, XLI-B1, 991-998. [CrossRef]

91. Kelcey, J.; Lucieer, A. Sensor correction of a 6-band multispectral imaging sensor for UAV remote sensing. Remote Sens. 2012, 4, 1462-1493. [CrossRef]

92. Von Bueren, S.K.; Burkart, A.; Hueni, A.; Rascher, U.; Tuohy, M.P.; Yule, I.J. Deploying four optical UAV-based sensors over grassland: Challenges and limitations. Biogeosciences 2015, 12, 163-175. [CrossRef]

(C) 2020 by the authors. Licensee MDPI, Basel, Switzerland. This article is an open access article distributed under the terms and conditions of the Creative Commons Attribution (CC BY) license (http://creativecommons.org/licenses/by/4.0/). 